\title{
The Dynamics of the Global Monsoon: Connecting Theory and Observations
}

\author{
Ruth Geen $^{1}$, Simona Bordoni ${ }^{2,3}$, David S. Battisti ${ }^{4}$, Katrina Hui $^{3}$ \\ ${ }^{1}$ College of Engineering, Mathematics and Physical Sciences, University of Exeter, Exeter, UK. \\ ${ }^{2}$ Department of Civil, Environmental and Mechanical Engineering, University of Trento, Trento, Italy. \\ ${ }^{3}$ California Institute of Technology, Pasadena, CA, USA. \\ ${ }^{4}$ Dept. of Atmospheric Sciences, University of Washington, Seattle, WA, USA.
}

\section{Key Points:}

- Theoretical understanding of the dynamics of Hadley cells, monsoons and ITCZs is developing rapidly

- Connecting theory to the observed monsoons helps in understanding variability and future projections

- Key limitations include the lack of firm theoretical frameworks for zonal asymmetries and transients

Corresponding author: Ruth Geen, rg419@exeter.ac.uk 


\begin{abstract}
Earth's monsoons are complex systems, governed by both large-scale constraints on the atmospheric general circulation and regional interactions with continents and orography, and coupled to the ocean. Monsoons have historically been considered as distinct regional systems, and the prevailing view has been, and remains, an intuitive picture of monsoons as a form of large-scale sea breeze, driven by land-sea contrast. However, climate dynamics is seldom intuitive. More recently, a perspective has emerged within the observational and Earth system modeling communities of a global monsoon that is the result of a seasonally migrating tropical convergence zone, intimately connected to the global tropical atmospheric overturning and localized by regional characteristics. Parallel with this, over the past decade, much theoretical progress has been made in understanding the fundamental dynamics of the seasonal Hadley cells and Intertropical Convergence Zones via the use of hierarchical modeling approaches, including highly idealized simulations such as aquaplanets. Here we review the theoretical progress made, and explore the extent to which these theoretical advances can help synthesize theory with observations and understand differing characteristics of regional monsoons. We show that this theoretical work provides strong support for the migrating convergence zone picture, allows constraints on the circulation to be identified via the momentum and energy budgets, and lays out a framework to assess variability and possible future changes to the monsoon. Limitations of current theories are discussed, including the need for a better understanding of the influence of zonal asymmetries and transients on the large-scale tropical circulation.
\end{abstract}

\title{
Plain Language Summary
}

The monsoons are the wet summer circulations that provide most of the annual rainfall to many countries in the tropics, influencing over one third of the world's population. Monsoons in different regions have historically been viewed as separate continentscale 'sea breezes', where land heats faster than ocean in the summer, causing warm air to rise over the continent and moist air to be drawn over the land from the ocean. Recent theoretical advances and the latest analyses of monsoon circulations support a rather different picture. We show that both theories and observations support a view of the monsoons as being localized seasonal migrations of the tropical convergence zone: the band of converging air and rainfall in the tropics embedded within the tropical atmospheric overturning circulation. This updated perspective explains commonalities and differences in behaviour between the regional monsoons, and may help to better understand yearto-year variability in the monsoons, and how the global monsoon might change in future. We end by discussing features of the monsoons that are not yet fully included in this new picture, such as the influence of mountains and continent shapes on the circulation, and the relationship of the monsoons with shorter lived weather systems.

\section{Introduction}

Monsoons are a dominant feature of the tropical and subtropical climate in many regions of the world, characterized by rainy summer and drier winter seasons, and accompanied by a seasonal reversal of the prevailing winds. Fig. 1a shows the difference in precipitation (GPCP; Huffman et al., 2001) and 850-hPa wind velocity (JRA-55; Kobayashi et al., 2015) between June-September and December-March, based on a climatology from 1979-2016. Strong seasonal differences can be seen throughout the tropics and subtropics, localized by the position of the continents. The magenta contour marks regions where local summer minus winter precipitation exceeds $2.5 \mathrm{~mm} /$ day and summer accounts for at least $55 \%$ of the annual total precipitation and thus identifies the various monsoon regions around the globe.

For practical purposes, such as agriculture, it has generally been of interest to explore the controls on seasonal rainfall at a regional scale. On the interannual to intrasea- 

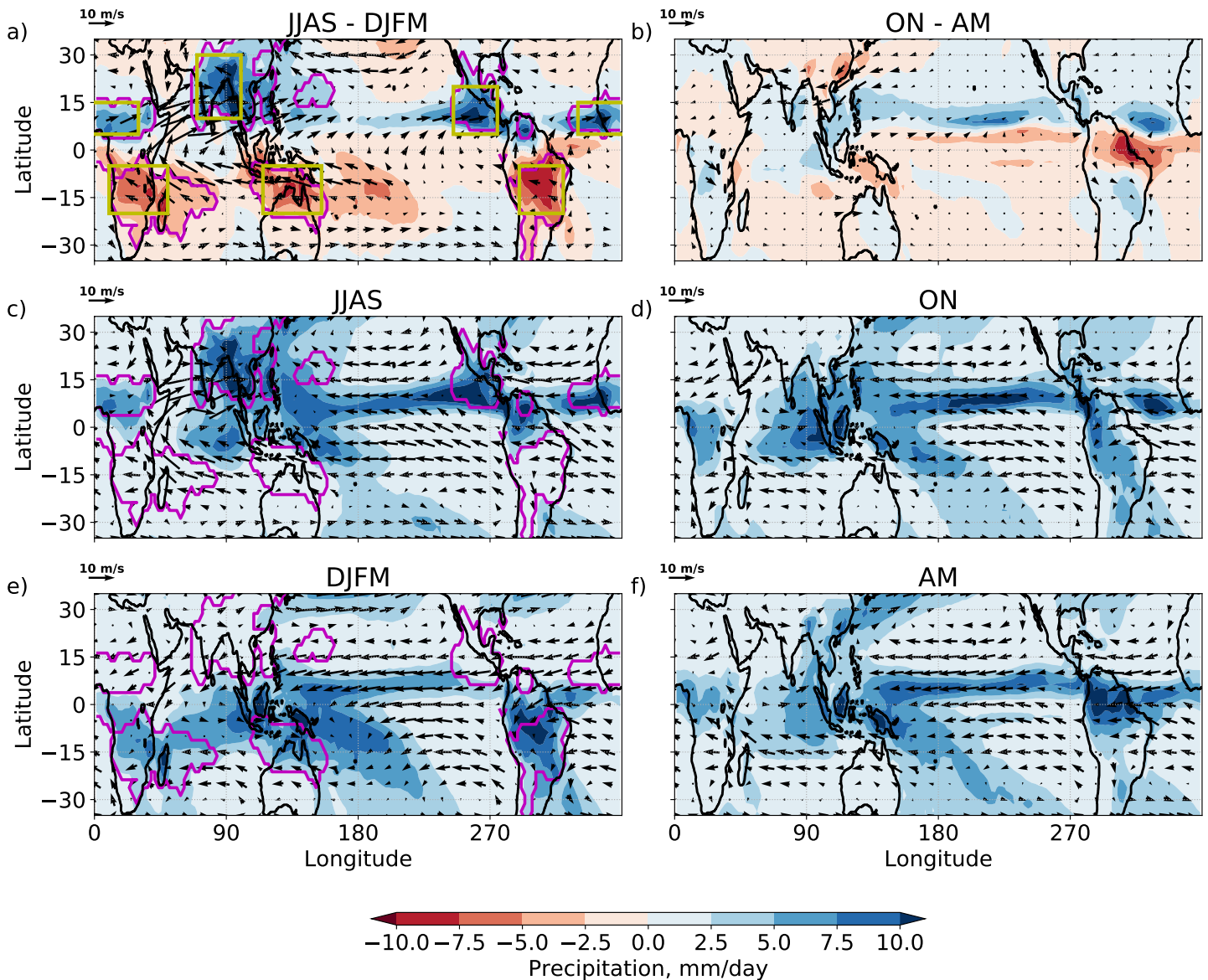

Figure 1. (a) Difference in precipitation (colors) and 850-hPa wind speed (arrows) between Northern Hemisphere summer (defined as June-September) and Southern Hemisphere summer (defined as December-March). (c) and (e) show Northern and Southern Hemisphere summer precipitation and wind respectively. In these panels the magenta contour indicates regions where local summer minus winter precipitation exceeds $2.5 \mathrm{~mm}$ /day and summer accounts for at least $55 \%$ of the annual total precipitation. Yellow boxes in (a) approximate these regions for use in Fig. 2. (b), (d) \& (f) are as (a), (c) \& (e) but for shoulder seasons defined as October \& November and April \& May.

sonal timeframe, the local monsoons behave as distinct systems, with interannual variability in precipitation showing limited similarity between regions (Fig. 2). However, as paleoclimate proxy, observational and reanalysis datasets have become more comprehensive and reliable, it has become possible to investigate variability on longer timescales; a comprehensive review is given in P. X. Wang et al. (2014). These datasets reveal that, on orbital timescales, the regional monsoons respond coherently to Milankovitch cycles, on millennial timescales they show similar responses to high latitude forcings, and on interdecadal timescales they also share common trends and modes of variability (e.g. Biasutti et al., 2018; J. C. Chiang \& Friedman, 2012; Schneider, Bischoff, \& Haug, 2014; B. Wang \& Ding, 2006; P. X. Wang et al., 2014). For example, Fig. 3 shows data from a range of paleoclimate proxies, which indicate that tropical rainfall in South America, Indonesia and India covaries with Arctic temperatures on millennial timescales. 
Northern Hemisphere

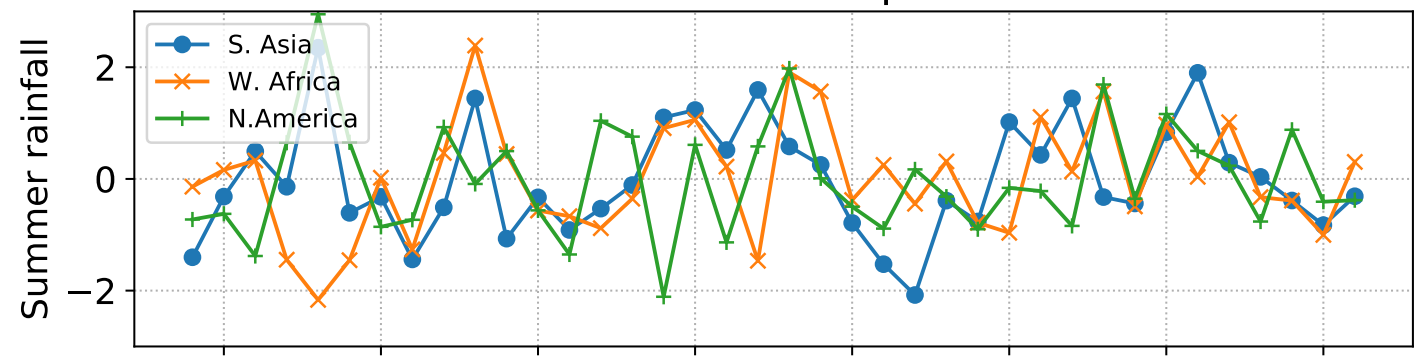

Southern Hemisphere

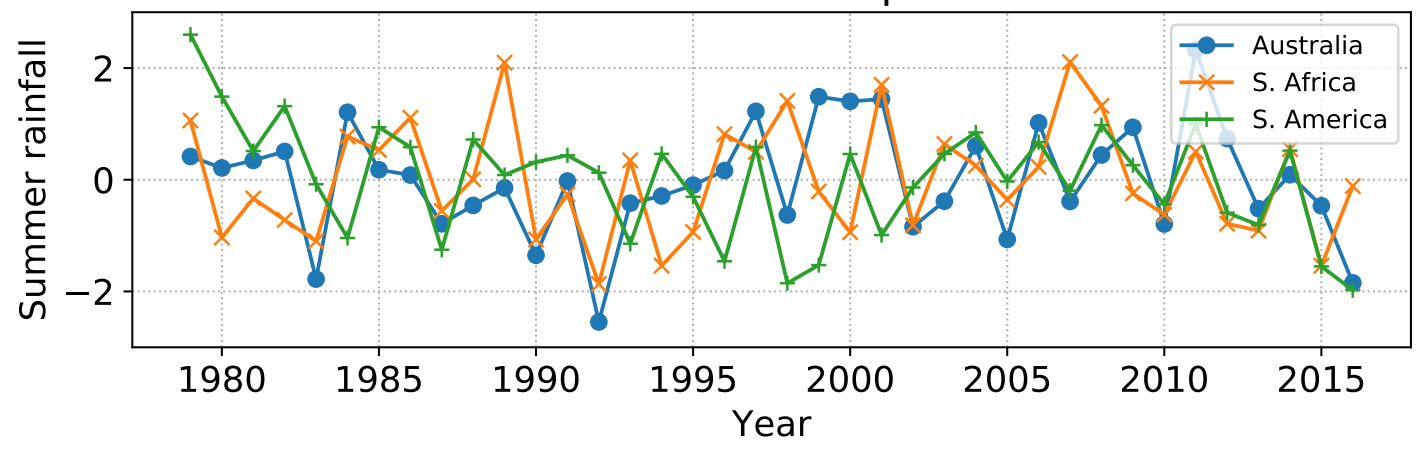

Figure 2. Timeseries of summer-time (July-September mean in the Northern Hemisphere and December-March mean in the Southern Hemisphere) rainfall over the yellow boxes marked in Fig. 1, which are used as approximations to the monsoon regions defined by the magenta contour. For ease of comparison, the timeseries are standardized by subtracting the mean and dividing by the standard deviation. Data are taken from the Global Precipitation Climatology Project (GPCP; Huffman et al., 2001) over 1979-2016.

This evidence for coherent global-scale monsoons raises questions about our physical understanding of the systems. Historically, the localization of summertime tropical rainfall around land led to the intuitive interpretation of monsoons as a large-scale sea breeze, with moist air drawn over the continent in the local summer season, when the land is warm relative to the ocean, resulting in convective rainfall over land (Halley, 1686). Monsoons were considered distinct phenomena to the Intertropical Convergence Zone (ITCZ), which is generally defined as the convergence of the trade winds of the Northern and Southern Hemispheres and is embedded within the ascending branches of the Hadley circulations. This perspective of monsoons as a sea breeze has been pervasive, despite the fact that land-sea temperature contrast has long been known to be greatest prior to monsoon onset over India (Simpson, 1921), and that drought years are accompanied by higher land surface temperatures (Kothawale \& Kumar, 2002). More recent work suggests a perspective of the monsoons as localized and more extreme migrations of the tropical convergence zone, which may sit near the Equator forming an ITCZ, or be pulled poleward over the continent as a monsoon (see Gadgil, 2018, and references therein).

Simultaneously, a significant body of work investigating the fundamental dynamics of the monsoon has been undertaken via hierarchical modeling approaches, ranging from dry axisymmetric models (e.g. Bordoni \& Schneider, 2010; Hill, Bordoni, \& Mitchell, 2019; Schneider \& Bordoni, 2008), to cloudless moist models (e.g. Bordoni \& Schneider, 2008; Faulk, Mitchell, \& Bordoni, 2017; Geen, Lambert, \& Vallis, 2018, 2019; Privé \& Plumb, 2007a), to more comprehensive models including full physics and realistic orog- 


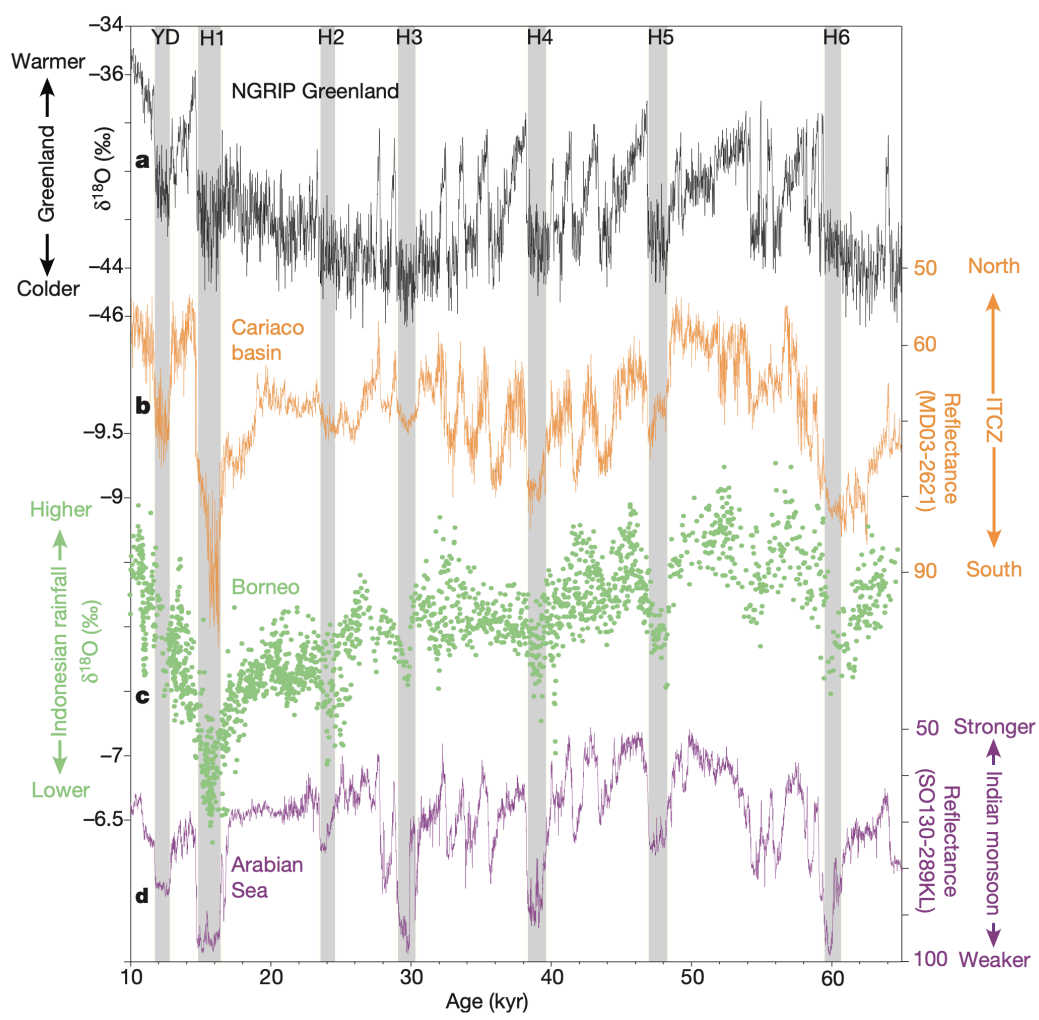

Figure 3. Paleoclimate proxy records from over the past 64,000 years. (a) Record of $\delta^{18} \mathrm{O}$ from the North Greenland Ice Core Project, a proxy for Arctic temperatures (Bond et al., 1993; Wolff et al., 2010). (b) Reflectance of Cariaco basin sediments, which is high when rainfall and runoff are low, and is used here as a proxy for the latitude of the ITCZ in the western tropical Atlantic (Deplazes et al., 2013). (c) $\delta^{18} \mathrm{O}$ in cave stalagmites from Borneo (Carolin et al., 2013), a proxy for rainfall in the equatorial western Pacific. (d) Reflectance of Arabian Sea sediments (Deplazes et al., 2013); low reflectance indicates high runoff from Indian monsoon rainfall. Figure taken from Schneider et al. (2014).

raphy (e.g. Boos \& Kuang, 2010; Chen \& Bordoni, 2014). This hierarchy has allowed a wide range of factors controlling the structure of tropical precipitation to be explored. Findings from these studies strongly support the view of monsoons as local expressions of the global tropical convergence zone, and provide valuable, theoretically grounded insights into the controls on the tropical circulation.

In this review, we attempt to synthesize the results of studies on the observed characteristics of Earth's monsoon systems with recent theoretical analyses that provide constraints on the large-scale dynamics of monsoons, with the aim of taking stock of the progress achieved and identifying avenues for future work. Note that throughout the review, 'monsoon' refers to the local summer, as opposed to winter, monsoon. Specifically, as we will motivate through discussion of theoretical work, we reserve the term 'monsoon' to describe precipitation associated with cross-equatorial overturning circulations with ascending branches located poleward of $\sim 10^{\circ}$ latitude. We will show that, unlike the ITCZs, these circulations are not strongly influenced by momentum transport by large-scale extratropical eddies. The term 'ITCZ' is instead reserved to describe the zonally oriented precipitation bands that remain within $\sim 10^{\circ}$ of the Equator and whose dynamics are much more strongly influenced by large-scale eddies. The term convergence zone will be 
used to refer to both monsoonal and ITCZ precipitation because, regardless of their governing dynamics, both are associated with ascending branches of overturning cells.

The goals of this article are:

1. To assess the relevance of idealized modeling results to the real-world monsoons;

2. To help to motivate relevant simulations from the modeling community to answer open questions on monsoon dynamics;

3. To provide an introduction to both of these aspects for readers new to the field.

With these aims in mind, Section 2 discusses theoretical results derived from idealized models, particularly aquaplanets with symmetric boundary conditions and heating perturbations. Section 3 discusses the features of the observed regional monsoons, their combined role in the global monsoon, and the applicability of the dynamical processes identified in idealized models to the various systems. Section 4 explores the roles of asymmetries in the boundary conditions and transient activity in the monsoons and ITCZs. These factors are sometimes overlooked in formulating theories in idealized models. In Section 5 we summarize the successes and limitations of this synthesis of theory and observations, and propose some areas on which to focus future research.

\section{Idealized modeling of monsoons}

Reanalyses, observations, and state of the art global circulation models (GCMs) give our best estimates of Earth's climate. However, when viewed as a whole, the Earth system is dizzyingly complex, and identifying the processes controlling the various elements of climate is hugely challenging. Idealized models provide a valuable tool for breaking down some of this complexity, and for proposing mechanisms whose relevance can then be investigated in more realistic contexts. ${ }^{2}$ In this section, we review the use of idealized models in understanding the dynamics of the monsoons.

Some key insights into the controls on tropical rainfall and monsoons have come from a perhaps unexpected source: aquaplanets. Despite lacking zonal asymmetries such as land-sea contrast, which localize regional monsoons, these models have been shown to capture the basic elements of a monsoon. For example, in aquaplanets with moist physics and a low thermal inertia slab ocean, the ITCZ migrates rapidly away from the Equator into the summer hemisphere during the warm season (Bordoni \& Schneider, 2008). This migration of the ITCZ is associated with a rapid reversal of the upper- and lowerlevel wind in the summer hemisphere, and the onset of intense off-equatorial precipitation, similar to the behaviors seen in Earth's monsoons, (e.g. Fig. 4). Thus, in so far as the rapid development of an off-equatorial convergence zone accompanied by similarly rapid circulation changes can be interpreted as a monsoon, aquaplanets provide a simple tool for exploring the lowest-order processes at work. This represents a significant change in perspective from the classical view of monsoon wind reversal as driven by landsea thermal contrast (Halley, 1686), towards a view of monsoons as local and seasonal manifestations of the Hadley circulation.

Different theoretical approaches have been used to interpret the results from these idealized simulations, primarily using large-scale budgets of energy and angular momentum. The momentum budget gives insight into the drivers and regimes of the overturning circulation, and how these relate to monsoon onset. The energy budget provides a

\footnotetext{
${ }^{1}$ NB Mixed layer depths here are corrected from Bordoni and Schneider (2008), (S. Bordoni, pers. com., 2020).

${ }^{2}$ For further discussion of the use of idealized models and the model hierarchy see (Held, 2005; Jeevanjee, Hassanzadeh, Hill, \& Sheshadri, 2017; Maher et al., 2019)
} 

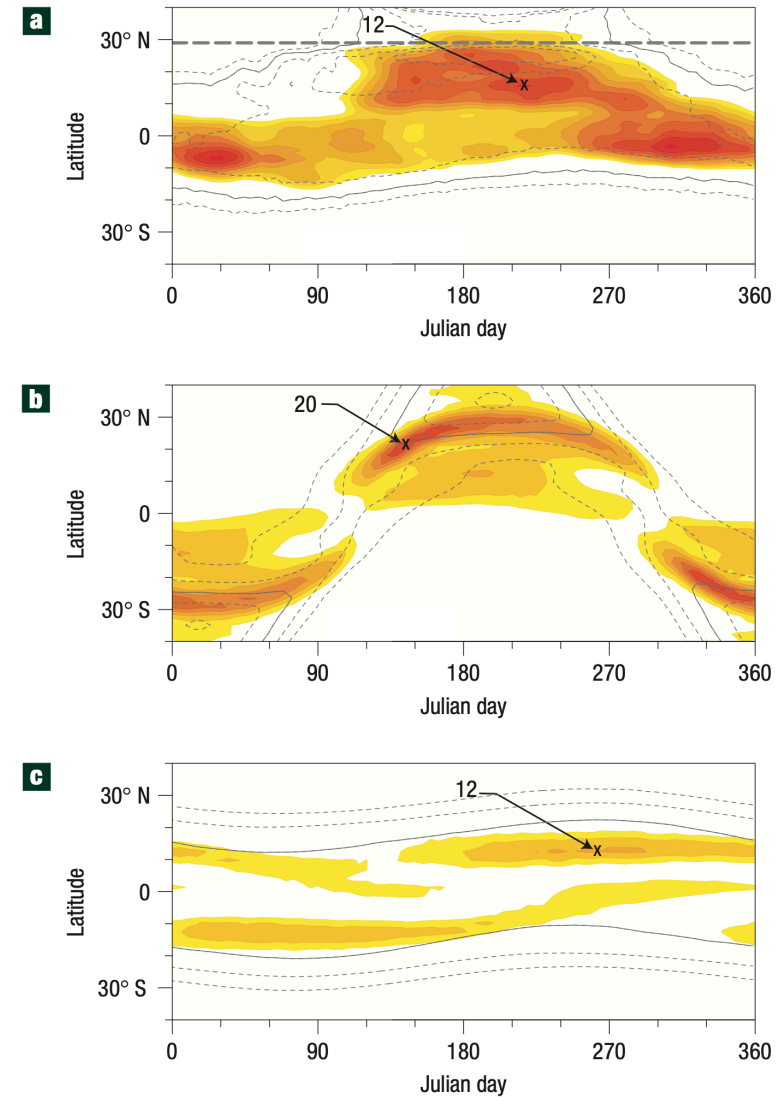

Figure 4. Seasonal cycle of zonal- and pentad- mean precipitation (color contours, data from GPCP 1999-2005) and sea-level air temperature (gray contours, data from the ERA-40 reanalysis (Uppala et al., 2005)) for (a) observations in the Asian monsoon sector (70-100 ${ }^{\circ} \mathrm{E}$ ), and for aquaplanet simulations with ocean mixed-layer heat capacity equivalent to (b) $0.5 \mathrm{~m}$ and (c) $50 \mathrm{~m}$ of water. ${ }^{1}$ The precipitation contour interval is $1 \mathrm{~mm} /$ day in (a) and $2 \mathrm{~mm} /$ day in (b) and (c), and maxima are indicated by crosses. For sea-level air temperature, the contour interval is $2^{\circ} \mathrm{C}$ in all panels, and the solid gray line indicates the $24^{\circ} \mathrm{C}$ isoline. The thick dashed line in (a) shows the latitude at which the zonal-mean topography in the Asian monsoon sector rises above $3 \mathrm{~km}$. Figure taken from Bordoni and Schneider (2008).

framework for understanding the controls on the latitude of the zonally averaged ITCZ, and its meridional migration. In a real world context, this is useful in interpreting the latitude of tropical rainfall bands, and the meridional extent of Earth's monsoons. These complementary approaches are discussed in Sections 2.1 and 2.2, respectively.

\subsection{Dynamical constraints}

One important constraint on the atmospheric circulation is conservation of angular momentum. Recent results from aquaplanet simulations suggest that this can help to explain controls on the latitude of the convergence zone, the extent of the Hadley circulation, and the rapidity of monsoon onset. 
The axial component of the angular momentum associated with the atmospheric circulation is

$$
M=\Omega a^{2} \cos ^{2} \phi+u a \cos \phi,
$$

where $\Omega$ and $a$ are Earth's rotation rate and radius, $u$ is the zonal wind speed, and $\phi$ is latitude. Equation 1 states that the atmosphere's angular momentum comprises a planetary contribution from Earth's rotation, and a contribution from the zonal wind relative to this. In the absence of torques, e.g. from friction, zonal pressure gradients or orography (see Egger, Weickmann, \& Hoinka, 2007), $M$ is conserved by an air parcel as it moves meridionally. Above orography, in the zonal mean we can approximate

$$
\frac{D M}{D t}=0 \text {. }
$$

Substituting Eq. 1 into Eq. 2, linearising about the zonal and time mean state, and considering upper-level flow where viscous damping is weak and can be neglected gives

$$
\bar{v}\left(f-\frac{1}{a \cos \phi} \frac{\partial(\bar{u} \cos \phi)}{\partial \phi}\right)-\bar{\omega} \frac{\partial \bar{u}}{\partial p}=\frac{1}{a \cos ^{2} \phi} \frac{\partial\left(\overline{u^{\prime} v^{\prime}} \cos ^{2} \phi\right)}{\partial \phi}+\frac{\partial \overline{u^{\prime} \omega^{\prime}}}{\partial p} .
$$

Overbars indicate the time and zonal mean, and primes deviations from the time mean. ${ }^{3}$ $v$ and $\omega$ are the meridional and vertical wind components, respectively. Terms relating to the mean flow have been grouped on the left hand side, while terms relating to eddy fluxes of momentum are grouped on the right. Assuming that meridional streamlines are near horizontal in the upper branch of the Hadley circulation, so that the vertical derivatives can be neglected, and utilising the definition of relative vorticity, $\zeta=\hat{\mathbf{k}} \cdot \nabla \times \mathbf{u}$, Eq. 3 can be expressed in terms of a local Rossby number, $R o=-\bar{\zeta} / f$, (cf. Schneider \& Bordoni, 2008) as

$$
f(1-R o) \bar{v}=\frac{1}{a \cos ^{2} \phi} \frac{\partial\left(\overline{u^{\prime} v^{\prime}} \cos ^{2} \phi\right)}{\partial \phi} .
$$

\subsubsection{The axisymmetric case}

Considering first the case of an axisymmetric atmosphere, in which there are no eddies, Eq. 4 has two classes of solution. Firstly, the zonal averaged meridional and (by continuity) vertical velocities may be zero everywhere. This corresponds to a radiativeconvective equilibrium (RCE) solution. Alternatively, Ro may be equal to 1 and an axisymmetric circulation may exist, so that the zonal and time mean flow conserves angular momentum. Plumb and Hou (1992) and Emanuel (1995) explored the conditions under which either of these cases might occur in dry and moist atmospheres, respectively. Importantly, the RCE solution is not viable if the resulting zonal wind in thermal wind balance with the RCE temperatures violates Hide's theorem (Hide, 1969) by giving rise to a local extremum in angular momentum. Plumb and Hou (1992) demonstrate that for an off-equatorial forcing, this implies the existence of a threshold curvature of the lowerlevel RCE temperature, above which the RCE solution cannot exist and an overturning circulation will develop. They also speculate that this threshold behavior in the axisymmetric model might be related to the rapid onset of Earth's monsoons. The overall argument is as follows.

Taking the RCE case, in which $v$ and $\omega$ vanish, gradient wind and hydrostatic balance can be expressed in pressure coordinates as

$$
\frac{\partial}{\partial p}\left[f u_{e}+\frac{u_{e}^{2} \tan \phi}{a}\right]=\frac{1}{a}\left(\frac{\partial \alpha}{\partial \phi}\right)_{p},
$$

where $\alpha$ is specific volume and $u_{e}$ is a RCE zonal wind profile. For a dry atmosphere, assuming the zonal wind speed at the surface is zero, the above can be integrated down

\footnotetext{
${ }^{3}$ Since we are in an aquaplanet framework, there are no eddy transports by stationary waves.
} 
to the surface for a given upper-level wind profile to give an associated RCE lower-level temperature distribution (cf. Lindzen \& Hou, 1988; Plumb \& Hou, 1992).

In modeling Earth's atmosphere, moist processes must also be accounted for. In the tropics, frequent, intense moist convection means that in the time mean, the lapse rate is approximately maintained as a moist adiabat, so that the saturation moist entropy of the free atmosphere is nearly equal to the subcloud moist entropy, $s_{b}$ (the $b$ denoting subcloud values) (e.g. Arakawa \& Schubert, 1974; Emanuel, Neelin, \& Bretherton, 1994). This is known as convective quasi-equlibrium (CQE). Assuming the tropical atmosphere to be in CQE, Emanuel (1995) uses Eq. 5 to derive a relation between the angular momentum at the tropopause, $M_{t}$, and subcloud equivalent potential temperature, $\theta_{e b}$ :

$$
c_{p}\left(T_{s}-T_{t}\right) \frac{\partial \ln \theta_{e b}}{\partial \phi}=-\frac{1}{a^{2}} \frac{\tan \phi}{\cos ^{2} \phi}\left(M_{t}-\Omega^{2} a^{4} \cos ^{4} \phi\right),
$$

where $T_{s}$ and $T_{t}$ are the RCE temperatures at the surface and tropopause respectively, $c_{p}$ is the heat capacity of dry air at constant pressure and $\theta_{e b}$ is related to moist entropy as $s_{b}=c_{p} \ln \theta_{e b}$. The condition that no local maximum in angular momentum exist gives a critical curvature of $\theta_{e b}$ :

$$
-\left[\frac{\partial}{\partial \phi}\left(\frac{\cos ^{2} \phi}{\tan \phi} c_{p}\left(T_{s}-T_{t}\right) \frac{\partial \ln \theta_{e b}}{\partial \phi}\right)\right]_{c r i t}=4 \Omega^{2} a^{2} \cos ^{3} \phi \sin \phi .
$$

In an axisymmetric atmosphere, if the left hand side of Eq. 7 is less than than the right hand side, the RCE solution is viable and there is no meridional overturning cell. Where this condition is violated, so that the profile of $\theta_{e b}$ is supercritical, the RCE solution is not viable and a meridional flow must exist (cf. Emanuel, 1995; Hill et al., 2019; Plumb \& Hou, 1992). This condition is illustrated graphically in Fig. 5, which shows the profiles of RCE zonal wind, angular momentum, and absolute vorticity (proportional to the meridional gradient of angular momentum) that result from a range of forcings with a subtropical maximum and flat elsewhere, Fig. 5a. ${ }^{4}$ For weak forcing (blue lines), no extrema of $M$ are produced, illustrated by the fact that absolute vorticity (Fig. 5d) is positive everywhere. At the critical forcing profile (gray lines) a saddle point in $M$ is produced, where absolute vorticity is 0 . Beyond this point, the profiles of $u$ that are in gradient wind balance with the forcing are such as to produce extrema in $M$, and are in violation of Hide's theorem (Hide, 1969) so that a Hadley circulation must develop.

The above arguments assess the conditions under which a Hadley circulation will exist in an axisymmetric atmosphere. Privé and Plumb (2007a) further showed that this framework can give some insight into the controls on the latitude of the ITCZ. They noted that, for an overturning circulation that conserves angular momentum in the free troposphere, the circulation boundary for a vertical streamline must be located in a region of zero vertical wind shear. Where CQE applies, so that free tropospheric temperatures are coupled to lower-level $\theta_{e b}$, this implies that the zero streamfunction contour must occur in a region of zero horizontal gradient of $\theta_{e b}$ (i.e. where $\theta_{e b}$ maximizes). Most of the ascent in the circulation ascending branch, and consequently the precipitation, will occur just equatorward of this maximum. They additionally noted that either the maximum in $\theta_{e b}$ or the maximum in moist static energy (MSE), $h$, could also be used to estimate the latitude of the convergence zone (see their Section 5$)^{5}$, as the two variables are related by

$$
\partial \theta_{e b} \approx \frac{1}{T_{b}} \partial h_{b}
$$

\footnotetext{
${ }^{4}$ NB. This figure, taken from Hill et al. (2019), corresponds to a dry atmosphere, cf. Plumb and Hou (1992), but the behavior is equivalent to that for Eq. 7 .

${ }^{5} \theta_{e}$ is useful due to its relationship to moist entropy, which for example allows the substitution of a Maxwell relation into Eq. 5 (Emanuel, 1995). However, MSE is a linear quantity that is straightforward to calculate, and so is more widely used.
} 

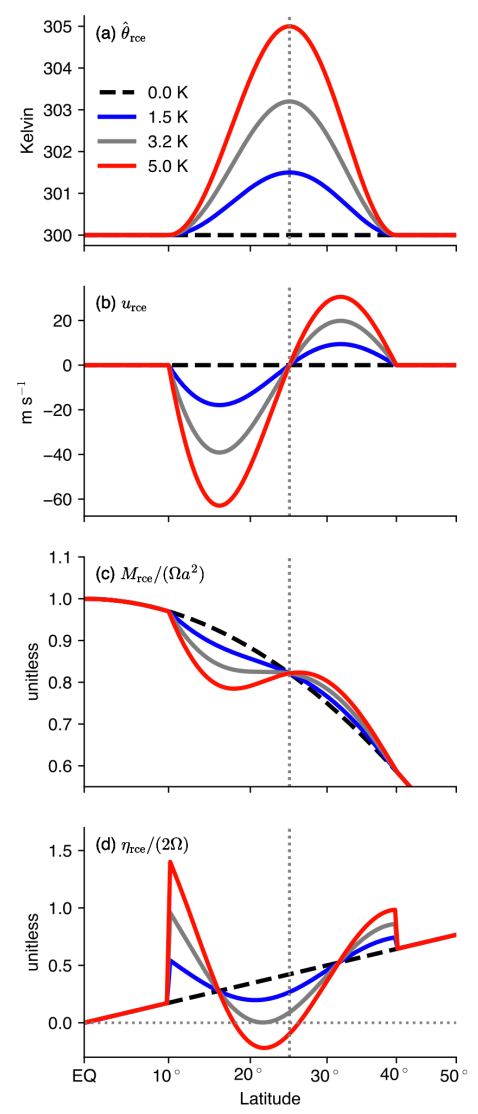

Figure 5. Illustration of the effects of a subcritical (blue lines), critical (gray lines) or supercritical (red lines) RCE potential temperature profile. Forcing profiles, shown in (a), are based on those used by Plumb and Hou (1992). The remaining panels show (b) zonal wind (ms $\left.{ }^{-1}\right)$, (c) absolute angular momentum, normalized by the planetary angular momentum at the Equator, (d) absolute vorticity, normalized by twice the planetary rotation rate. Figure taken from Hill et al. (2019). (c) American Meteorological Society. Used with permission.

$$
h=c_{p} T+L_{v} q+g z .
$$

In the above, $T$ is temperature, $q$ is specific humidity, $z$ is height, $L_{v}$ is the latent heat of vaporisation of water, and $g$ is gravitational acceleration.

\subsubsection{Eddy-permitting solutions}

These theoretical considerations, based on conservation of angular momentum, provide important constraints on the existence and extent of axisymmetric overturning circulations. However, it is now well known that extratropical eddies, generated in midlatitude baroclinic zones, propagate into the subtropics where they break, and have nonnegligible impact on the Hadley circulation (e.g. Becker, Schmitz, \& Geprägs, 1997; C. C. Walker \& Schneider, 2006). In particular, as transport of angular momentum by large-scale eddies becomes non-negligible, the associated eddy momentum flux convergence in Eq. 4 can no longer be neglected. In the limit of small Ro, the mean meridional advection of zonal momentum is negligible, and the dominant balance is between the Coriolis effect on the zonal mean meridional flow and the eddy momentum flux divergence. This regime is linear, in that the mean advection term is negligible, and eddy driven, in that the strength 
(a)

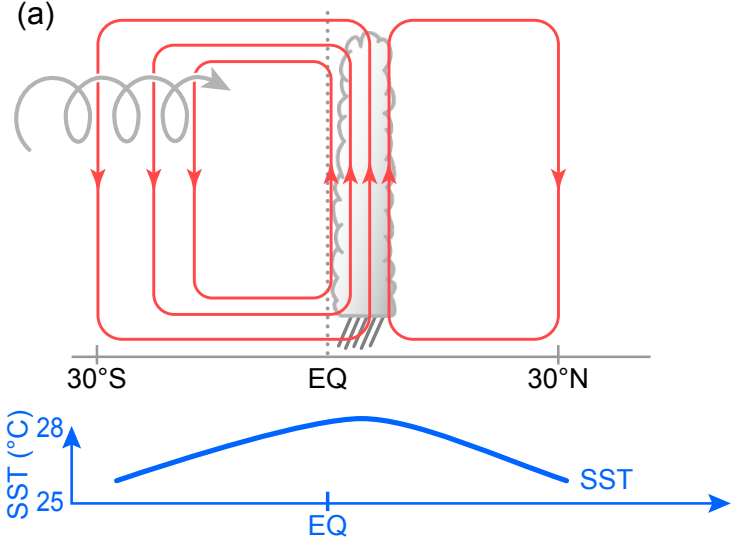

(b)

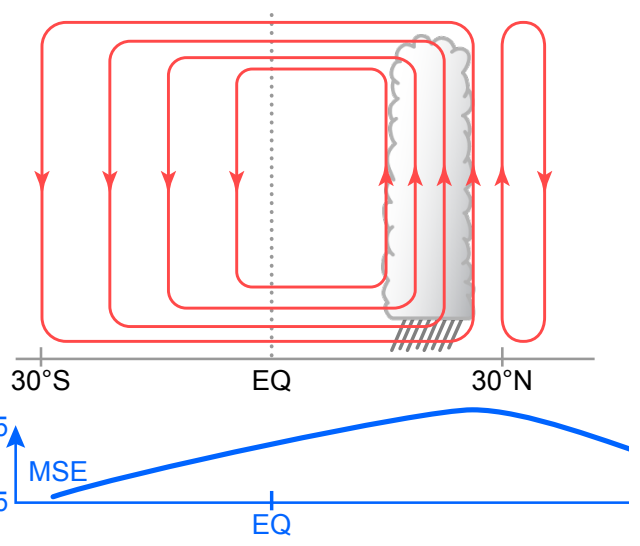

Figure 6. Schematic illustration of the two regimes of the meridional overturning circulation identified in aquaplanets (Bordoni \& Schneider, 2008; Schneider \& Bordoni, 2008). The gray cloud denotes clouds and precipitation, red contours denote streamfunction. (a) Convergence zone is an ITCZ located near to the Equator, and approximately co-located with the peak SST. Hadley cells are significantly eddy driven, as indicated by the helical arrow. (b) Convergence zone is monsoon-like, located farther from the Equator, with the mid-tropospheric zero contour of the streamfunction aligned with the moist static energy (MSE) maximum (Privé \& Plumb, 2007b) and precipitation falling just equatorward of this. The winter Hadley cell crosses the Equator and is near angular-momentum conserving, with eddies only weakly influencing the overturning strength. The summer Hadley cell is comparatively weak, if present at all. Illustration by Beth Tully.

of the circulation is constrained by the eddy momentum fluxes. In reality, intermediate cases, with $R o \sim 0.5$, are also observed, where both nonlinear zonal mean advection and eddy terms are important.

Transitions from regimes with small $R o$ to regimes with $R o$ approaching unity have been connected to the rapid changes in the tropical circulation that occur during monsoon onset. Examining the upper-level momentum budget in aquaplanet simulations with a seasonal cycle, Bordoni and Schneider (2008) found that, while the Hadley cells in the two hemispheres are roughly symmetric and the associated convergence zone is near the Equator, Ro $\lesssim 0.5$, and the circulation strength is governed by eddies (e.g. Fig. 6a). As the insolation maximum starts moving into the summer hemisphere, the winter Hadley cell starts becoming cross equatorial. The zonal mean ascent and precipitation move to an off-equatorial location in the summer hemisphere (e.g. Fig. 4), and upper-level tropical easterlies develop. These limit the ability of eddies from the winter hemisphere to propagate into the low latitudes, and the circulation shifts quickly towards the $R o \sim 1$ angular momentum conserving flow regime, at the same time strengthening and expanding rapidly (e.g. Fig. 6b). As the cross-equatorial circulation approaches conservation of angular momentum, the dominant balance becomes between the terms on the left hand side of Eq. 3, with the eddy terms a small residual. Once in this regime, the circulation is no longer constrained by the zonal momentum budget, which becomes a trivial balance, but is constrained by the energy budget, and so responds strongly to the thermal forcing.

The rapid meridional migrations of the convergence zone in the aquaplanet are a result of a positive feedback relating to advection of cooler and drier air up the MSE gra- 
dient in the lower branch of the winter Hadley cell, illustrated in Fig. 7. As summer begins the summer hemisphere warms via diabatic fluxes of MSE into the air column (Fig. 7b). This pulls the lower-level peak in MSE and, in accordance with the arguments of Privé and Plumb (2007a), pulls the ITCZ off of the Equator. Simultaneously, the winter Hadley circulation begins to redistribute MSE, advecting cooler and drier air up the MSE gradient (Figs. 7c\&d). The gradient of MSE steepens, amplifying the thermal forcing of the cell. The overturning circulation strengthens in response to this, further increasing the lower-level advection of cooler air, and expanding the upper-level easterlies, allowing the circulation to become further shielded from the eddies. It is important to note that in this view land is necessary for monsoon development only insofar as it provides a lower boundary with low enough thermal inertia for the MSE to adjust rapidly and allowing the feedbacks described above to act on intraseasonal timescales. Behavior consistent with these feedbacks has been observed in Earth's monsoons, and will be discussed in more detail in Section 3.

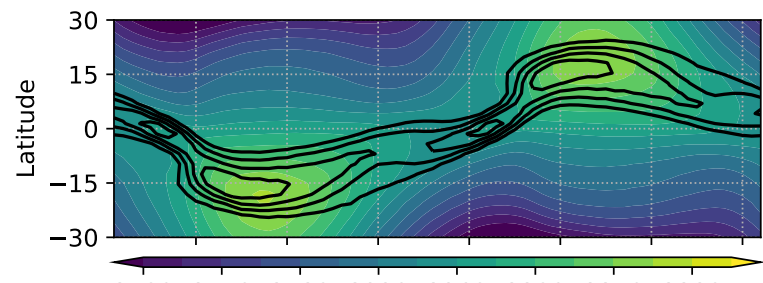

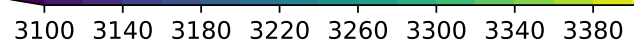
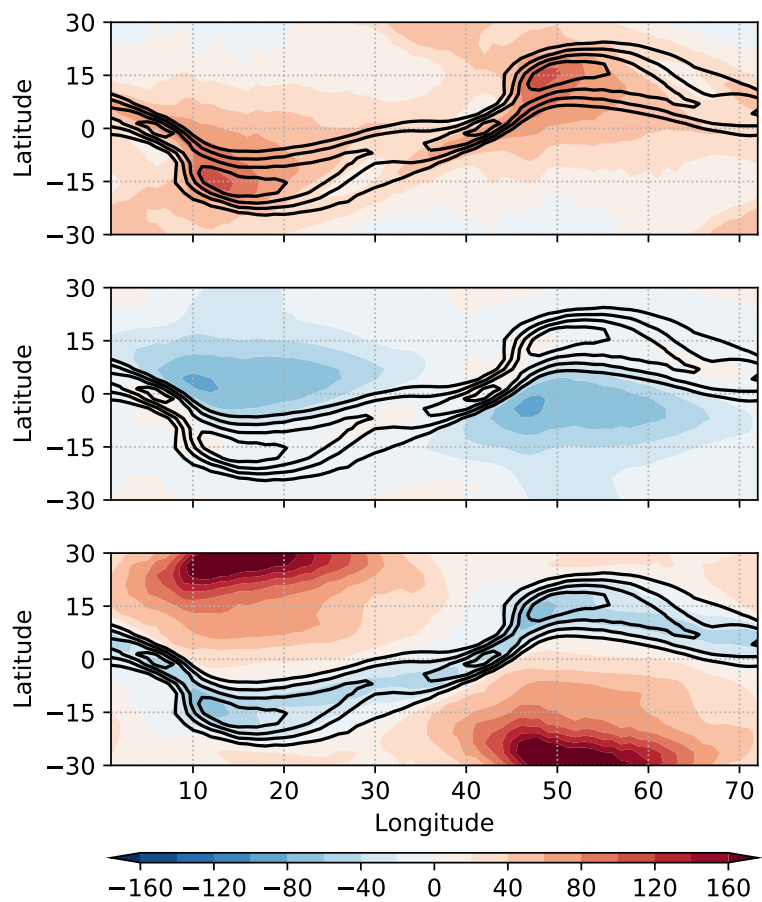

Figure 7. Zonal- and pentad- mean of terms in the moist static energy budget for an aquaplanet simulation with surface heat capacity equivalent to $10 \mathrm{~m}$ of water. Panel (a) shows the vertically integrated moist static energy, $h$ (units $\mathrm{MJm}^{-2}$ ). Panels (b-d) show $F_{\text {net }}$ (the net flux of radiation, latent and sensible heat into the column), $-v \partial h / \partial y$, and $-\omega \partial h / \partial p$ respectively (units $\mathrm{Wm}^{-2}$ ). 


\subsubsection{Hadley cell regimes and the latitude of the ITCZ}

The idealized modeling work discussed above indicates that the Hadley cells in an aquaplanet change their circulation regime over the course of the year, varying rapidly between an eddy-driven 'ITCZ' regime and a near angular-momentum conserving 'monsoon' regime. In addition, that the cross-equatorial Hadley cell approaches angular momentum conservation suggests that axisymmetric theories (e.g. Equation 7) might not be applicable to the understanding of the zonal and annual mean Hadley cell, but might provide important constraints on monsoonal circulations, which do approach an angular momentum conserving state. The relationship between these two regimes and the latitude of the ITCZ raises further questions: How far into the summer hemisphere must the Hadley cell extend for the regime transition, and associated rapid shift in ITCZ latitude, to occur? Does the latitude at which the convergence zone shifts from being governed by 'ITCZ' to 'monsoon' dynamics in aquaplanets relate to the observed latitudes of the ITCZs and monsoons? If the Hadley cell boundary follows the peak in MSE (Privé \& Plumb, 2007a), what governs the extent of the cross-equatorial cell, e.g. is a pole-topole cell possible?

Geen et al. (2019) investigate the first of the above questions. By running aquaplanet simulations under a wide range of conditions, including different slab ocean depths, year lengths, and rotation rates, they investigated how the ITCZ latitude and migration rate were related, and how these factors varied over the year. They found that, at Earth's rotation rate, the ITCZ appeared least stable (migrated poleward fastest) at a latitude of $7^{\circ}$, suggesting that this may be the poleward limit of an eddy-driven overturning circulation fuelled by an ITCZ. Beyond this latitude there is a rapid transition to a monsoon circulation characterized by an overturning circulation with a rising branch far off the Equator and weak eddy momentum transports. This 'transition latitude' does not vary significantly with surface heat capacity or year length, but it does increase with decreasing planetary rotation rate. Although the mechanism governing the transition latitude is not yet fully understood, this $7^{\circ}$ threshold might give a guideline for where the tropical precipitation is dynamically associated with a near-equatorial 'ITCZ' vs. a monsoon system.

Consistent with these results, simulations with zonally symmetric continents extending poleward from southern boundaries with different latitudes show that monsoonal convergence zones extending into the subtropics and featuring a rapid onset can only develop over a continent extending to tropical latitudes (up to $20^{\circ}$ ). For continents with more poleward southern boundaries, the main precipitation zone remains close to the Equator and moves more gradually into the summer hemisphere. The absence of regions of low thermal inertia in the tropical region in this second case prevents the establishment of a reversed meridional MSE gradient and, with it, the poleward displacement of the circulation ascending branch and convergence zone (Hui \& Bordoni, in prep.).

While the results from this idealized work can help differentiate between oceanic ITCZs vs land monsoons, it is worth noting that the observed ITCZs over the Atlantic and Pacific are in fact located away from the Equator, and migrate between $4^{\circ}$ and $12^{\circ}$ over the year (see Figs. 1 and 8). There is considerable evidence that the off-equatorial position of these ITCZs is a result of a symmetric instability in the boundary layer flow (Levy \& Battisti, 1995; Stevens, 1983; Tomas \& Webster, 1997). Symmetric instability is a two-dimensional (latitude-height) instability that results from the joint criteria of conservation of angular momentum and potential temperature (potential vorticity). ${ }^{6}$ The instability in the boundary layer flow is set up by cross-equatorial pressure gradients, driven by equatorially asymmetric boundary layer heating. This may result from either a zon-

\footnotetext{
${ }^{6}$ For motion on a constant potential temperature (angular momentum) surface, the criteria reduces to the criteria for inertial (convective) instability (Emanuel, 1988; Tomas \& Webster, 1997).
} 

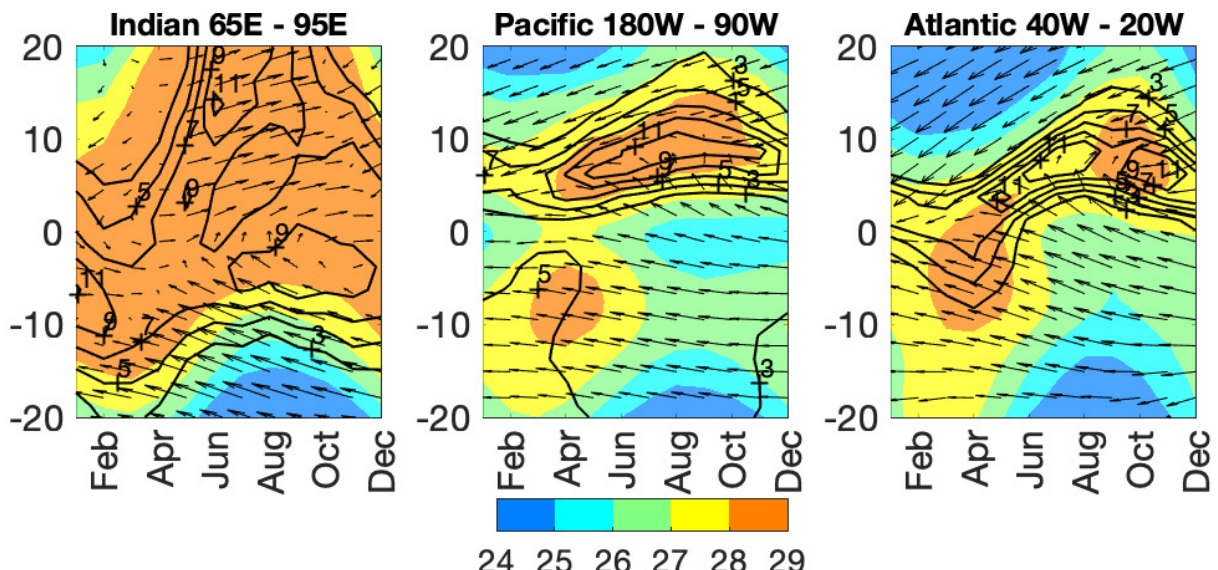

Figure 8. Hovmoller diagram of the climatological SST and 10m wind (1979-2017), averaged across the (left) Indian, (center) eastern half of the Pacific and (right) Atlantic basin. SST is shaded (in ${ }^{\circ} \mathrm{C}$ ) and precipitation is contoured (contour interval $2 \mathrm{~mm} /$ day). The wind vectors are relative to the maximum in each panel. Precipitation data are from CMAP 1979-2017 (Xie \& Arkin, 1997a), SST data are from HADISST 1870-2017 (Rayner et al., 2003), and wind data are from ERA-Interim 1979-2017 (Dee et al., 2011). From Battisti et al. (2019). (C)American Meteorological Society. Used with permission.

ally asymmetric sea surface temperature (SST) distribution (see Back \& Bretherton, 2009; J. C. H. Chiang, Zebiak, \& Cane, 2001; Lindzen \& Nigam, 1987, and references thererin) or from asymmetric land heating (e.g., the West African summer monsoon). The result of the instability is a band of divergence in the boundary layer that lies between the Equator and the latitude of neutral stability, flanked by a narrow zone of convergence that lies just poleward and provides the moisture convergence that fuels the ITCZ convection. The role of symmetric instability was not considered by Geen et al. (2019), who ran only simulations where the annual mean ITCZ location was on the Equator. Further aquaplanet simulations, with for example ocean heat transport prescribed such as to set up an annual mean asymmetric boundary layer pressure gradient, may help in understanding how these various instabilities and feedbacks interact during the seasonal transitions of the Hadley cells.

The application of the theoretical concepts discussed in Sections 2.1.1 and 2.1.2 to Hadley cell extent has been addressed in recent work by Faulk et al. (2017), Hilgenbrink and Hartmann (2018), Hill et al. (2019) and Singh (2019). Faulk et al. (2017) performed a series of simulations using an eddy-permitting aquaplanet model in which they varied rotation rate under seasonally varying insolation. They found that, at Earth's rotation, the MSE maximized at the summer pole, but the ITCZ did not migrate poleward of $\sim 25^{\circ}$ from the Equator even in perpetual solstice simulations, contrary to expectations from Privé and Plumb (2007a). The influence of eddies on the cross-equatorial circulation was found to be weak, consistent with the suppression of eddies by upper-level easterlies (Bordoni \& Schneider, 2008; Schneider \& Bordoni, 2008) and justifying the use of axisymmetric based considerations as a starting point for understanding the cell extent. Faulk et al. (2017) found that a Hadley circulation existed over the latitudes where the curvature of $\theta_{e b}$ was supercritical (see Eq. 7), with the curvature subcritical in the extratropics.

Other authors have used axisymmetric theory to examine what determines the maximum Hadley cell extent. For example, Hill et al. (2019) applies axisymmetric arguments 
to show that an angular momentum conserving cell must extend at least as far into the winter hemisphere as the summer hemisphere. In eddy-permitting atmospheres, the Hadley cell edge is often viewed as related to the latitude at which the upper-level wind shear becomes baroclinically unstable (e.g. Held \& Coauthors, 2000). Hilgenbrink and Hartmann (2018) found that the reduced upper-level zonal velocity associated with an ITCZ located further from the Equator tends to reduce vertical wind shear, and consequently baroclinicity, over the winter hemisphere cell edge, so that the cell extends deeper into the winter hemisphere.

While these studies have provided novel insight into important features of crossequatorial Hadley cells, prognostic theories for their poleward boundary in the summer hemisphere have yet to emerge. Singh (2019) investigated the limitations of CQE-based predictions based on the lower-level MSE maximum. The vertical instability addressed by CQE is not the only form of convective instability in the atmosphere. If vertical wind shear is strong, CQE predicts an unstable state in which potential energy is released when saturated parcels move along slantwise paths, along angular momentum surfaces (Emanuel, 1983a, 1983b). Singh (2019) showed that the perpetual solstitial cell extent can be accurately estimated by assuming that the large-scale circulation adjusts the atmosphere towards a state that is neutral to this slantwise convection. When the peak in subcloud moist entropy is relatively close to the Equator, the cell boundary is near vertical and the atmosphere is near CQE, and this reduces to the condition of Privé and Plumb (2007a).

Notably, this developing body of literature indicates that the planetary rotation rate determines the latitudinal extent of the Hadley cell, potentially limiting the maximum latitudinal extent of a monsoon circulation. This might provide a guideline for distinguishing a monsoon associated with a cross-equatorial Hadley cell and governed by tropical dynamics, where the convergence zone is located with $\sim 25^{\circ}$ of the Equator (e.g. South Asia) from a monsoon strongly influenced by extratropical processes, where summer rainfall is observed at higher latitudes (e.g. East Asia).

\subsection{Energetic constraints}

The regional monsoons are an integral part of the ITCZ, here interpreted as the longitudinal band of maximal tropical rainfall. One important step in understanding monsoon dynamics has therefore been an exploration of the mechanisms governing the behavior of the zonally averaged ITCZ. For example, in the annual and zonal mean, the ITCZ is located in the Northern Hemisphere (at $1.7^{\circ} \mathrm{N}$ if estimated by the precipitation centroid; Donohoe, Marshall, Ferreira, and Mcgee (2013), or $\sim 6^{\circ} \mathrm{N}$ if judged by the precipitation maximum; e.g. Gruber, Su, Kanamitsu, and Schemm (2000)). While it is usually the case that the ITCZ is co-located with SST maxima, both paleoclimate proxies (e.g. Fig. 3; Arbuszewski, Demenocal, Cléroux, Bradtmiller, \& Mix, 2013; Lea, Pak, Peterson, \& Hughen, 2003; McGee, Donohoe, Marshall, \& Ferreira, 2014) and model simulations (Broccoli, Dahl, \& Stouffer, 2006; J. C. H. Chiang \& Bitz, 2005; R. Zhang \& Delworth, 2005) indicate that the ITCZ responds to extratropical forcing, that is, to forcing remote from its location. Analysis of the atmospheric and oceanic energy budget has helped to explain these behaviors.

Not surprisingly, aquaplanet simulations have been used to examine systematically controls on the ITCZ latitude by imposing a prescribed hemispherically asymmetric forging in the extratropics and varying its strength. Kang, Held, Frierson, and Zhao (2008) found that the atmospheric energy transport associated with the Hadley cell largely compensates for changes in hemispherically asymmetric extratropical surface heating. The Hadley cell diverges energy away from its ascending branch, i.e. away from the ITCZ, and generally transports energy in the direction of the upper-level meridional flow. Hence a hemispherically asymmetric atmospheric heating will cause the ITCZ to shift towards the hemisphere with the greater heating, as illustrated in Fig. 9. Kang et al. (2008) fur- 


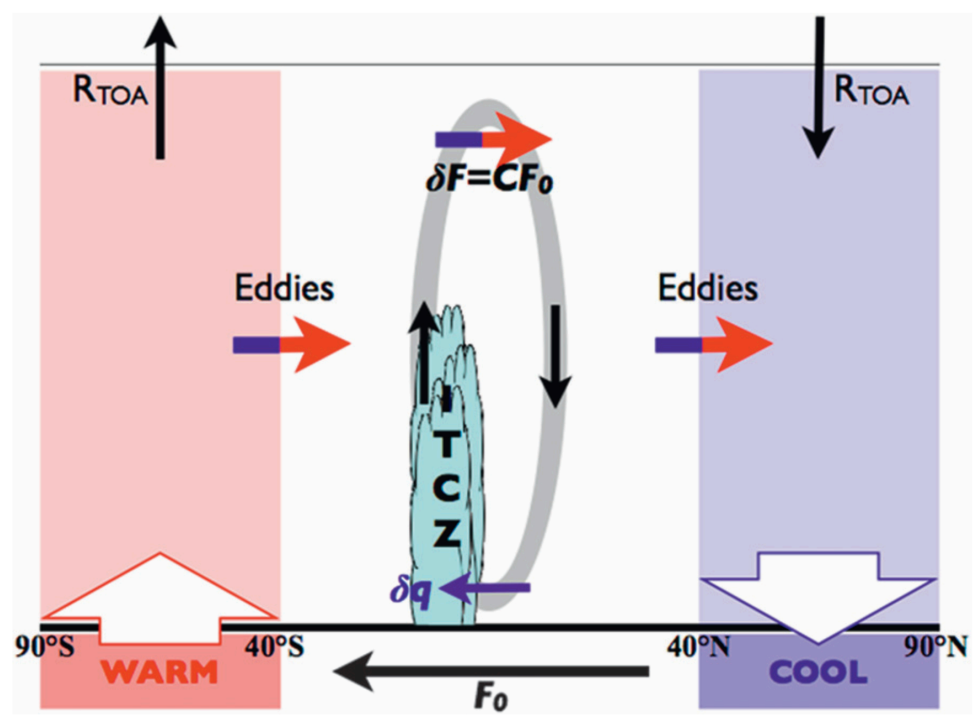

Figure 9. Schematic illustrating the energetics framework to determine the tropical response to extratropical thermal forcing (Kang et al., 2009). Warming is applied to the southern extratropical slab ocean, giving an implied ocean heat transport anomaly $F_{o}$. The atmosphere compensates for the additional warming by altering the top-of-atmosphere net radiative flux $\left(R_{T O A}\right)$ and horizontal energy transports by the atmosphere. In the tropics, the gray oval indicates the anomalous Hadley circulation response, the direction of which is represented by black arrows. The blue (red) part of the colored arrow indicates regions where energy transports act to (anomalously) cool (warm) the atmosphere. These energy transports are due to midlatitude eddies and the Hadley circulation. The clockwise anomalous Hadley circulation transports energy northward to cool (warm) the southern (northern) subtropics and largely compensates the warming (cooling) by eddies. This figure is taken from Kang et al. (2009). (C)American Meteorological Society. Used with permission.

ther noted that the ITCZ latitude was approximately colocated with the 'Energy Flux Equator' (EFE), the latitude at which the vertically integrated MSE flux is zero, and that it varied proportionally to the strength of the asymmetric forcing. This anticorrelation between the ITCZ latitude and the cross-equatorial atmospheric energy transport in the tropics has since been observed in aquaplanet models with different physical parametrisations (Kang et al., 2009), and in models with realistic continental configurations under global warming and paleoclimate scenarios (Donohoe et al., 2013; D. M. W. Frierson \& Hwang, 2012). In the zonal average, the latitudinal location of tropical precipitation appears more tightly controlled by changes in hemispheric asymmetry in surface energy flux forcing than by changes in SST (Kang \& Held, 2012), highlighting the power of this energetic framework. However, the degree of compensation between the imposed heating and the atmospheric energy transport is sensitive to the parameterisations of convection, clouds, and ice (D. M. W. Frierson \& Hwang, 2012; Kang et al., 2009, 2008), and to changes in energy transport by the ocean, which has been shown to play a significant role in the energy transport response to an imposed perturbation (Green \& Marshall, 2017; Levine \& Schneider, 2011; Schneider, 2017).

The relationship between the ITCZ, EFE, and tropical atmospheric energy transport can be understood more quantitatively using the steady state, zonally averaged, ver- 
tically integrated energy budget,

$$
\overline{\mathcal{S}}-\overline{\mathcal{L}}-\overline{\mathcal{O}}=\frac{\partial\langle\overline{v h}\rangle}{\partial y} .
$$

In the above, $\mathcal{S}$ is the net downward top of atmosphere shortwave radiation, $\mathcal{L}$ the outgoing longwave radiation and $\mathcal{O}$ represents any net energy uptake at the surface. Angular brackets denote a vertical integral, and overbars a time and zonal mean. Eq. 10 states that net energy input into the atmospheric column through top-of-atmosphere radiative fluxes and surface energy fluxes must be in balance with meridional convergence or divergence of MSE into the atmospheric column. For small meridional displacements, $\delta$, this equation can be Taylor expanded around the Equator to 3rd order as (Bischoff \& Schneider, 2014, 2016)

$$
\langle\overline{v h}\rangle_{\delta}=\langle\overline{v h}\rangle_{0}+a \partial_{y}\langle\overline{v h}\rangle_{0} \delta+\frac{1}{2} a^{2} \partial_{y y}\langle\overline{v h}\rangle_{0} \delta^{2}+\frac{1}{6} a^{3} \partial_{y y y}\langle\overline{v h}\rangle_{0} \delta^{3},
$$

where the ${ }_{0}$ subscript denotes quantities evaluated at the Equator. At the EFE, by definition, the vertically integrated, zonal mean MSE flux, $\langle\overline{v h}\rangle$, is zero. Taking $\delta$ as the latitude of the EFE, and substituting in from Eq. 10, gives

$$
0=\langle\overline{v h}\rangle_{0}+a(\overline{\mathcal{S}}-\overline{\mathcal{L}}-\overline{\mathcal{O}})_{0} \delta+\frac{1}{2} a^{2} \partial_{y}(\overline{\mathcal{S}}-\overline{\mathcal{L}}-\overline{\mathcal{O}})_{0} \delta^{2}+\frac{1}{6} a^{3} \partial_{y y}(\overline{\mathcal{S}}-\overline{\mathcal{L}}-\overline{\mathcal{O}})_{0} \delta^{3}
$$

The net energy input $(\overline{\mathcal{S}}-\overline{\mathcal{L}}-\overline{\mathcal{O}})$ is approximately symmetric about the Equator, so the quadratic term is small relative to the other terms (Bischoff \& Schneider, 2016), and can be neglected. Hence, to a good approximation, Eq. 12 can be written as

$$
\delta=-\frac{\langle\overline{v h}\rangle_{0}}{a(\overline{\mathcal{S}}-\overline{\mathcal{L}}-\overline{\mathcal{O}})_{0}} .
$$

Eq. 13 has been shown to give a good estimate of the EFE latitude under a range of warming scenarios in aquaplanets (Bischoff \& Schneider, 2014), and over the annual cycle in reanalysis (Adam, Bischoff, \& Schneider, 2016b). The EFE in turn acts as an indicator of the ITCZ latitude. More broadly, (Bischoff \& Schneider, 2016) found that the first order approximation is adequate when the net energy input at the Equator is large and positive, but that the cubic term is needed when this is small or negative. Notably the negative case corresponds to a double ITCZ.

Unfortunately, the ITCZ and EFE latitudes do not covary on all timescales. In particular these can deviate from one another significantly over the seasonal cycle (e.g. Adam et al., 2016b; Wei \& Bordoni, 2018). While the EFE denotes the latitude at which the meridional MSE flux changes sign, the ITCZ is associated with the ascending branch of the tropical meridional overturning circulation, which is close to the latitude where the mass flux changes sign. The energy flux and overturning circulation are related via the gross moist stability $\left(\Delta_{M}\right.$, defined here following e.g. D. M. W. Frierson, 2007; Hill, Ming, \& Held, 2015; Wei \& Bordoni, 2018):

$$
\Delta_{M}=\frac{\langle\overline{v h}\rangle}{\Psi_{\max }}=\frac{\langle\overline{v h}\rangle}{g^{-1} \int_{0}^{p_{m}} \bar{v} d p} .
$$

In the above, $\Psi_{\max }$ is the maximum of the overturning streamfunction, corresponding to the mass flux by the Hadley cell, and $p_{m}$ is the pressure level at which this maximum occurs. Considering Eq. 14 at the Equator, and combining with Eq. 13, we see that the strength of the Hadley circulation (and hence the ITCZ) will therefore covary with the EFE provided that the efficiency with which the Hadley cell transports energy, as captured by $\Delta_{M}$, remains approximately constant. However, recent aquaplanet simulations indicate that over the seasonal cycle $\Delta_{M}$ varies significantly, and in fact at times becomes negative, allowing the EFE and ITCZ to sit in opposite hemispheres (Wei \& Bordoni, 
2018). Gross moist stability has also been observed to vary significantly under changes to orbital precession in aquaplanet simulations (Merlis, Schneider, Bordoni, \& Eisenman, 2013). It is also worth noting that, in addition to variations in $\Delta_{M}$, the zonal mean energy flux compensating an energetic forcing may be achieved by transient eddies, rather than by changes to the zonal mean overturning circulation (Xiang, Zhao, Ming, Yu, \& Kang, 2018).

Despite these limitations, the energetic framework has been a major advance, and has given insight into variations in tropical rainfall over both the observational and paleo record (see review by Schneider et al., 2014, and references therein). One attractive feature of this perspective is that it provides a simple explanation for why, in the annual and zonal mean, the ITCZ sits in the Northern Hemisphere (Donohoe et al., 2013; Gruber et al., 2000). The energetic framework neatly shows that the ITCZ latitude can be understood as a result of the net flux of energy into the Northern Hemisphere by the ocean, in particular due to asymmetry introduced by the Drake passage (D. M. Frierson et al., 2013; Fučkar, Xie, Farneti, Maroon, \& Frierson, 2013; Marshall, Donohoe, Ferreira, \& McGee, 2014). Efforts to extend this framework to account for zonal asymmetry in the boundary conditions (the 'Energy Flux Prime Meridian' Boos \& Korty, 2016) are discussed in Section 3.2.

\section{Interpreting observations and modeled response to forcings}

In parallel with the theoretical developments described in Section 2, observational and reanalysis datasets have allowed more detailed analysis of the behavior of Earth's monsoons. As discussed in Section 1, one major step has been moving from a perspective of monsoons as individual, unrelated systems, to a perspective of a global monsoon manifesting itself into several regional systems (P. X. Wang et al., 2014, 2017, and references therein). In this section, we look at the insight into the dynamics of Earth's monsoons gained from observations and Earth System models, and at how it connects to the theoretical ideas developed using idealized model simulations discussed in Section 2. First, we give an overview of the characteristics of Earth's regional monsoons and ITCZs, and their role as part of the global monsoon. We then discuss the extent to which theory, particularly that from aquaplanet models, may help us understand the behavior of these systems in current climate, and offer possible constraints on future climate.

\subsection{The global and regional monsoons}

The magenta line in Fig. 1a-c marks out the regional monsoons, indicating areas where the local difference between summer and winter precipitation exceeds $2.5 \mathrm{~mm} /$ day, and where summer precipitation accounts for the majority of the annual total. Six regions can be identified: Asia, West Africa, Southern Africa, South America, North America and Australia (cf. S. Zhang \& Wang, 2008). The Asian monsoon is the most intense and largest in scale of these, and is often further divided into several subregions: the South Asian, East Asian, and Western North Pacific monsoons, as shown in Fig. 10. (B. Wang \& LinHo, 2002).

\subsubsection{Regional monsoon and ITCZ characteristics}

\section{South Asian Monsoon}

The South Asian monsoon features a wind reversal from winter easterlies to summer westerlies at low levels (e.g. B. Wang \& LinHo, 2002). Onset spreads from the south to the north, with the earliest onset of the system over the Southern Bay of Bengal, between late April and mid-May (Mao \& Wu, 2007), reaching Kerala between mid-May and mid-June (Ananthakrishnan \& Soman, 1988; J. M. Walker \& Bordoni, 2016; B. Wang, 


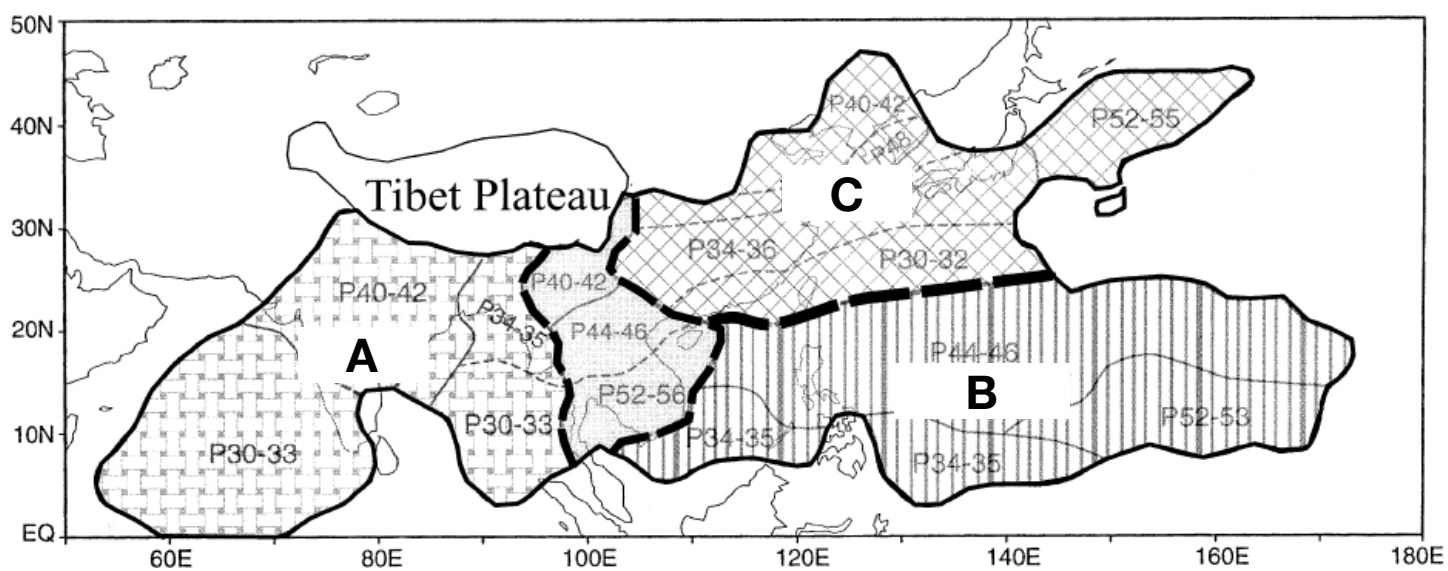

Figure 10. Map showing the division of the Asian monsoon into three subregions. The South Asian monsoon (A) and Western North Pacific monsoon (B) are tropical monsoon regions. A broad corridor in the Indochina Peninsula separates them. The subtropical monsoon region is identified as the East Asian monsoon (C), north of the Western North Pacific monsoon. Numbers indicate the pentad range during which the peak monsoon rainfall occurs. Adapted from B. Wang and LinHo (2002). (c) American Meteorological Society. Used with permission.

Ding, \& Joseph, 2009). Onset occurs over the South China Sea between early May and mid-June (B. Wang, LinHo, Zhang, \& Lu, 2004).

The wet season over India generally lasts from June to September, during which time about $78 \%$ of the total annual rain falls over India (Parthasarathy, Munot, \& Kothawale, 1994). The rain band withdraws towards the Equator between late September and early November (B. Wang \& LinHo, 2002).

\section{East Asian Monsoon}

While the South Asian monsoon is confined to latitudes southward of $\sim 30^{\circ} \mathrm{N}$, the East Asian monsoon extends north of this into the extratropics. Although the monsoon onset over the South China Sea has been considered a precursor to the East Asian monsoon onset (Martin et al., 2019; B. Wang et al., 2004), some authors (e.g. B. Wang \& LinHo, 2002) consider it as an entirely subtropical system, defining the East Asian monsoon region to include $\sim 20-45^{\circ} \mathrm{N}$ and $110-140^{\circ} \mathrm{E}$. A key element of the East Asian monsoon is an east-west oriented band of precipitation, known as Meiyu in China and Baiu in Japan, that is accompanied by a wind reversal from winter northerlies to summer southerlies. The Meiyu front brings intense rainfall to the Yangtze River valley and Japan from mid-June to mid-July, after which it breaks down and allows rainfall to extend into northern China and Korea. Prior to the onset of the Meiyu, South China experiences periods of rainfall in the form of the South China spring rain, intensifying from mid-March to May (Linho, Huang, \& Lau, 2008). A thorough review of the East Asian monsoon's characteristics, including its onset and development, governing processes and teleconnections is given in Ding and Chan (2005); see also Section 4.1.1.

\section{Western North Pacific Monsoon}

Monsoon rains arrive later over the Western North Pacific region (see Fig. 10) than the South and East Asian sectors, and last from July to October/November (B. Wang $\&$ LinHo, 2002). The monsoon advances from the south-west to north-east in a stepwise pattern associated with shifts in the Western North Pacific subtropical high (R. Wu \& 
Wang, 2001), while withdrawal occurs from the north-west to south-east (S. Zhang \& Wang, 2008). A predominantly zonally oriented change in wind direction is seen between winter and summer, associated with a weakening of the low-latitude easterly flow as the Western North Pacific subtropical high shifts eastward (e.g. Fig. 1).

\section{Indonesian-Australian Monsoon}

The Indonesian-Australian monsoon develops over Java in October-November, and progresses southeastward, reaching northern Australia in late December (Hendon \& Liebmann, 1990; S. Zhang \& Wang, 2008). During austral summer, the low-latitude easterlies over the western Maritime Continent reverse to a southwesterly flow, as seen in Fig. $1 \mathrm{~b}$ and c. Monsoon withdrawal occurs over northern Australia and the southeastern Maritime Continent through March, with the wet season persisting into April over Java (S. Zhang \& Wang, 2008).

\section{West African Monsoon}

The West African monsoon begins near the Equator, with intense rainfall over the Gulf of Guinea in April. This continues through to the end of June, with a second maximum developing near $10^{\circ} \mathrm{N}$ in late May. The peak precipitation is observed to jump rapidly to this second maximum in late June, accompanied by a reversal of the wind direction from north-easterly to south-westerly to the south of this maximum (Sultan \& Janicot, 2003). Precipitation weakens from August to September and the peak rainfall migrates back towards the Equator. Over the Sahel, the monsoon precipitation accounts for 75$90 \%$ of the total annual rainfall (Lebel, 2003).

\section{Southern African Monsoon}

The Southern African monsoon is offset longitudinally to the east of its Northern Hemisphere counterpart. The global monsoon onset metric of S. Zhang and Wang (2008) indicates that the rainy season begins in November over Angola and the southern DRC, and extends southeastward over the continent, progressing over southern Tanzania, Zambia and out over the ocean over northern Madagascar through December, and reaching Zimbabwe, Mozambique, and as far as the northeast of South Africa by January. The system extends out over the Southwestern Indian Ocean through January and February. Withdrawal occurs directed towards the north and west from February to April. In austral winter, the prevailing wind is southeasterly, but in summer this reverses to a weak northeasterly flow, with stronger northeasterly flow to the north of the region, over the Horn of Africa, as seen in Fig. 1c.

In the same longitudinal region, an East African monsoon is also discussed over the Greater Horn of Africa. Near the Equator, there are two wet seasons: the long rains from March to May, and the short rains from October-November (Nicholson, 2017). Farther to the north, from June to September a boreal summer wet season occurs in Ethiopia and Eritrea, with lower-level westerlies developing in June and persisting through to August (Segele \& Lamb, 2005).

\section{North American Monsoon}

The North American monsoon is observed as a marked increase in precipitation over the southwestern United States and Mexico, beginning in June-July, and withdrawing through September and October (Adams \& Comrie, 1997; Barlow, Nigam, \& Berbery, 1998; Ellis, Saffell, \& Hawkins, 2004). S. Zhang and Wang (2008) observed that onset (withdrawal) over this area occurs in a northward (southward) moving band. There is no large-scale reversal of the winds in this region (see Figs. 1b and 1c). However, the northwesterly flow down the coast of California observed in boreal winter weakens in boreal summer, the southeasterly flow over the east coast of Mexico strengthens, and the low-latitude easterlies over the eastern Pacific weaken in the Northern Hemisphere (e.g. 
Fig. 7, Barlow et al., 1998). In addition, at a smaller scale, the low-level wind direction reverses over the Gulf of California from northerly to southerly flow (Bordoni, Ciesielski, Johnson, McNoldy, \& Stevens, 2004).

\section{South American Monsoon}

The monsoon season in South America begins in October, with an abrupt shift of convection southward over the Amazon river basin (Marengo et al., 2012). The precipitation progresses southeastward through November and December (S. Zhang \& Wang, 2008). Withdrawal occurs from March to May, with the rain-band returning northward. During austral winter, the prevailing $850-\mathrm{hPa}$ winds over the continent are predominantly easterly between $10^{\circ} \mathrm{S}$ and $10^{\circ} \mathrm{N}$, but in summer the flow becomes northeasterly and cross equatorial, and a northwesterly jet, the South American Low-Level jet, develops along the east side of the Andes (Marengo et al., 2012). An upper-level anticyclone is observed over Bolivia, and a lower-level cyclone develops over northern Argentina (Rao, Cavalcanti, \& Hada, 1996). Central Brazil receives over $70 \%$ of its annual rainfall during the monsoon season, between September and February (Rao et al., 1996).

\section{The Atlantic and Pacific ITCZs}

The latitudinal position of the ITCZs in the Atlantic and Pacific also has a distinct seasonal cycle, as can be seen from the north-south dipole in the October/NovemberApril/May precipitation difference, shown in Fig. 1b. Over the continents, the latitudinal extremes in the position of the zonal average precipitation follows the Sun into the summer hemisphere and lags insolation by about a month due to the small heat capacity of the land-atmosphere system that participates in the seasonal cycle. In contrast, precipitation associated with the Atlantic and Pacific ITCZs reaches farthest north in October and farthest south (but still north of the Equator; see Section 4.1.3) in March about three months after the boreal and austral solstice, respectively (Fig. 8). These ITCZs tend to be located just equatorward of the warmest water in subtropical Northern Hemisphere, and the latter lags insolation by about three months due to the large heat capacity of the upper ocean that participates in the seasonal cycle.

The ITCZs are not a passive response to changes in SST, however: ocean-atmosphere interactions play a role in regulating the seasonal cycle of Atlantic and Pacific ITCZs (see Battisti, Vimont, \& Kirtman, 2019, and references therein). As the water warms the sea level pressure drops and the ITCZ moves northward (a hydrostatic response; see Lindzen \& Nigam, 1987); the cross-equatorial sea level pressure gradient increases, driving an increase in southerly winds near and just south of the Equator (Fig. 8) that increases the turbulent energy fluxes from the ocean to the atmosphere, cooling the ocean south of the Equator. This further increases the cross-equatorial pressure gradient and the southeasterly winds, which brings more moisture into the ITCZs.

\subsubsection{The Global Monsoon}

The regional monsoons exhibit a diverse range of behaviors, but some common features can be identified. From Fig. 1a, it can be seen that most monsoon regions feature anomalous westerly low-level flow in their summer season, with a cross-equatorial component directed into the summer hemisphere. However, comparing Figs. 1b and c shows that these anomalies are not always sufficient to cause a local reversal of the wind direction. Onset generally occurs as a poleward advancement of rainfall off of the Equator, often with an eastward directed progression. Onset also sometimes features sudden jumps or steps in the latitude (poleward) and longitude of precipitation, as observed over South Asia, West Africa, the Western North Pacific, and South America.

Paleoclimate reconstructions, present-day observations, and model simulations have begun to elucidate how the monsoons vary under a range of external and internal forc- 
ings. These findings were recently summarized comprehensively by P. X. Wang et al. (2014, 2017), An et al. (2015) and Seth et al. (2019). Forcings that preferentially warm or cool one hemisphere relative to the other, such as Heinrich events and changes in Earth's axial precession, are found to intensify the monsoons of the warmer hemisphere, and to weaken the monsoons of the cooler hemisphere (e.g. Battisti, Ding, \& Roe, 2014; H. Cheng, Sinha, Wang, Cruz, \& Edwards, 2012; Eroglu et al., 2016; Liu \& Battisti, 2015; Pausata, Battisti, Nisancioglu, \& Bitz, 2011; P. X. Wang et al., 2014). On interannual timescales, ENSO has also been found to modulate monsoon precipitation in both hemispheres, with El Niño associated with drying and La Niña associated with enhanced rainfall (B. Wang, Liu, Kim, Webster, \& Yim, 2012).

The above similarities in the climatology and variability of regional monsoons have motivated a view of the local monsoon systems as components of a global monsoon, which responds to forcings in a coherent manner. The global monsoon might be interpreted as the seasonal migration of the ITCZ from north to south throughout the year, with regional monsoons corresponding to locations where this migration is enhanced (e.g. Gadgil, 2018).

\subsection{Aquaplanet-like monsoons}

Aquaplanet-based theoretical work, as discussed in Section 2, has used symmetric boundary conditions to study the fundamental processes governing the zonal mean ITCZ, Hadley cells, and global monsoon. In contrast, the bulk of studies using observations, reanalysis, and Earth System models have tended to focus on the mechanisms controlling regional monsoons. While local factors are of great importance in determining the seasonal evolution and the variability of the individual monsoon systems, we argue here that aquaplanet results can inform us of unanticipated commonalities in the dynamics of the monsoons, and help us interpret the behaviors observed. Of the two perspectives discussed in Section 2 the energetic approach has received more attention (Biasutti et al., 2018; Schneider et al., 2014), perhaps due to the relative ease with which the relevant diagnostics can be evaluated and the intuitive picture it presents (Fig. 9). In this section we discuss how both approaches provide useful insights into the dynamics of Earth's monsoons.

\subsubsection{Insight from the momentum budget and CQE considerations}

For an aquaplanet, the momentum framework, combined with the assumption of CQE, indicates that:

1. The poleward boundary of a monsoon circulation lies just equatorward of the peak in subcloud MSE or $\theta_{e b}$ (Emanuel, 1995; Privé \& Plumb, 2007a, 2007b).

2. Cross-equatorial 'monsoon' Hadley cells approach conservation of angular momentum more than equinoctial cells, and consequently are more strongly coupled to meridional MSE gradients (Schneider \& Bordoni, 2008).

3. Rapid transitions can occur between an ITCZ regime (with two eddy-driven Hadley cells) and a monsoon regime with one dominant cell that extends into the summer hemisphere (cf. Figs. 6a and $6 \mathrm{~b}$ ). These transitions are mediated by feedbacks relating to advection of MSE in the lower branch of the Hadley circulation, and suppression of eddies by upper-level easterlies. (Bordoni \& Schneider, 2008, 2010; Schneider \& Bordoni, 2008).

4. At Earth's rotation rate, the transition from the eddy-driven to angular momentum conserving Hadley cell regime appears to occur at $\sim 7^{\circ}$ latitude on an aquaplanet with zonally symmetric boundary conditions (Geen et al., 2019). 
a)

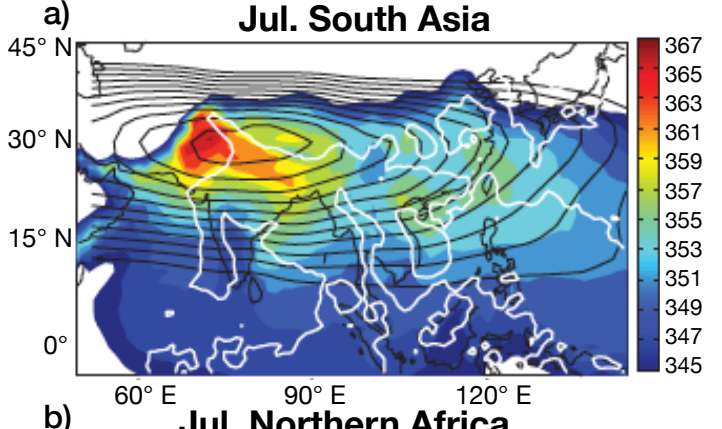

b)

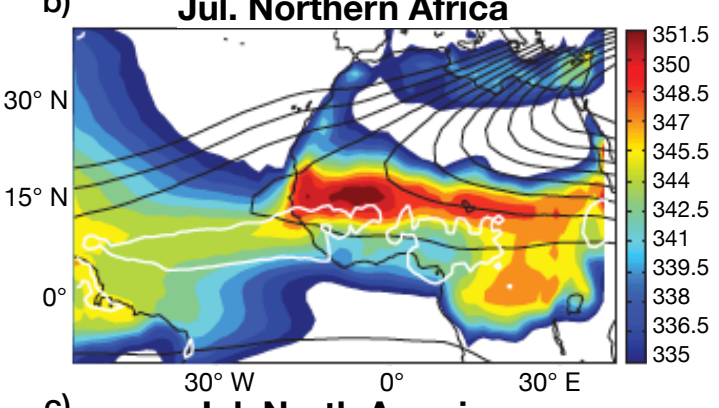

c) Jul. North America

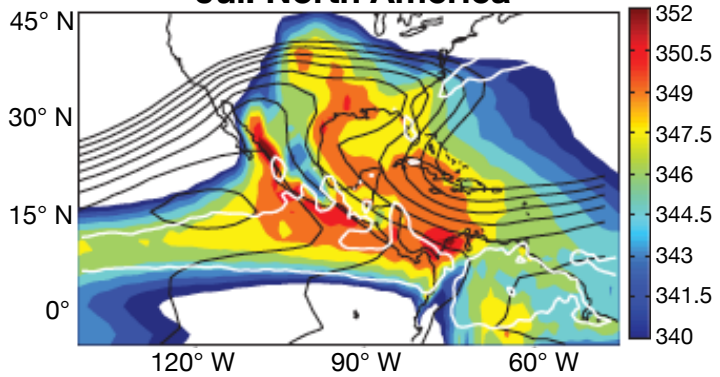

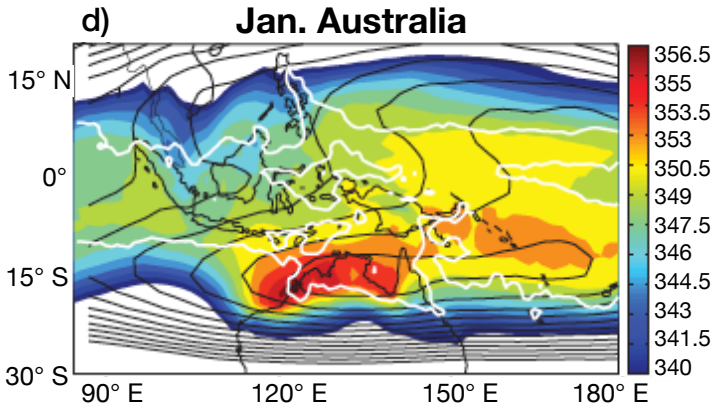

e) Jan. Southern Africa
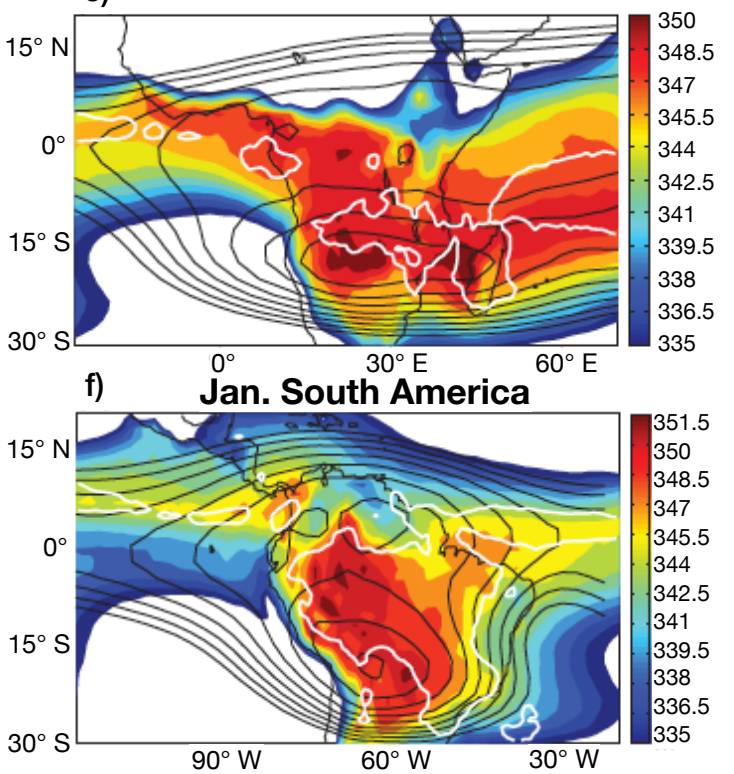

Figure 11. Evaluation of CQE for the (a) South Asia, (b) northern Africa, (c) North America, (d) Australia, (e) southern Africa and (f) South America monsoons. Colors show subcloud equivalent potential temperature, $\theta_{e b}$. The black contour is the free tropospheric saturation equivalent potential temperature, $\theta_{e}^{*}$, averaged from 200 to $400 \mathrm{hPa}$. The white contour indicates the region that has precipitation greater than 6 mmday $^{-1}$. The $\theta_{e}^{*}$ contours start from (a) $345 \mathrm{~K}$, (b) $340 \mathrm{~K}$, (c) $340 \mathrm{~K}$, (d-f) $341 \mathrm{~K}$ and the respective interval is (a) $1 \mathrm{~K}$, (b) $1 \mathrm{~K}$, and (c-f) $0.5 \mathrm{~K}$. Adapted from Nie et al. (2010). (c)American Meteorological Society. Used with permission.

5. At Earth's rotation rate, convergence zones within the ascending branches of seasonal cross-equatorial Hadley cells appear to be unable to migrate farther than $\sim 30^{\circ}$ from the Equator (Faulk et al., 2017; Hill et al., 2019; Singh, 2019).

The above ideas were developed in a very idealized framework, but consistent behavior has been observed on Earth. Nie et al. (2010) investigated whether the CQE assumption was relevant locally in the regional monsoons. By analysing ERA-40 and Tropical Rainfall Measuring Mission (TRMM) data, they demonstrated that, in the South Asian, Australian, and African monsoons, maxima of $\theta_{e b}$ and free-troposphere saturation equivalent potential temperature are approximately colocated, and peak precipitation indeed lies just equatorward of the peak in subcloud MSE, consistent with CQE predictions (Fig. 11). Also consistent with the idealized modeling work, seasonal changes in the character of the overturning circulation have been observed in the regional monsoons. The Hadley circulation over the South Asian monsoon region in particular has been highlighted as 

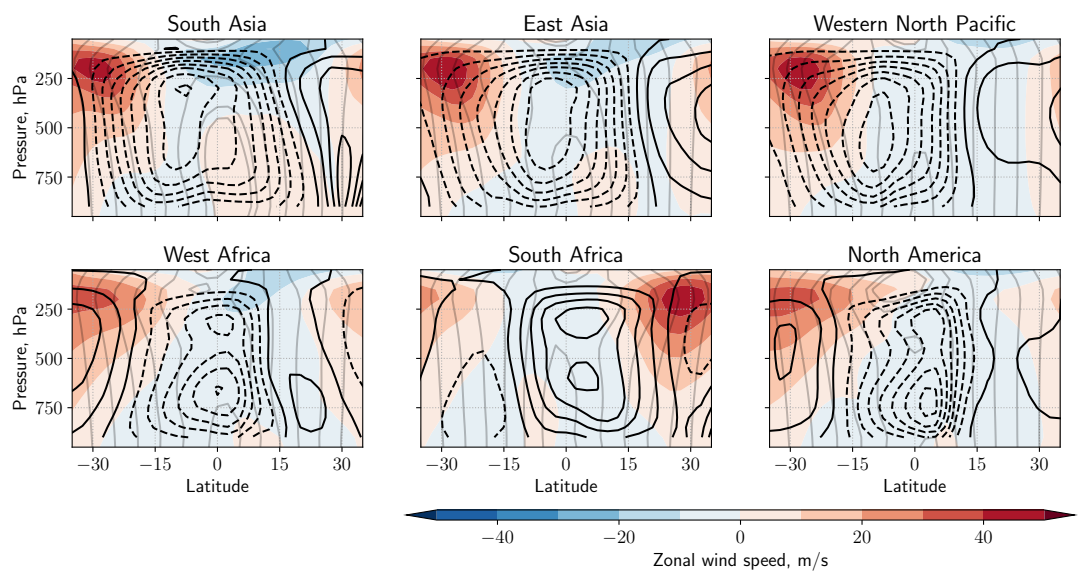

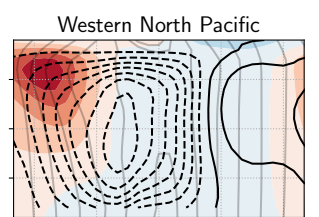

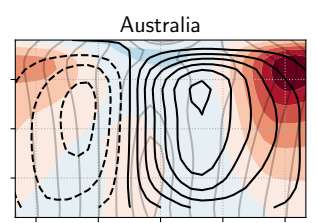

South America

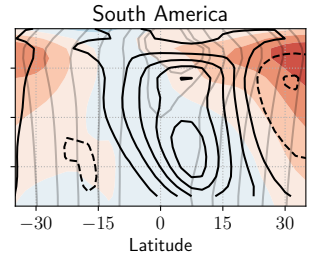

Figure 12. Black contours show local summer (June-September or December-March) meridional overturning circulations for: South Asia $\left(70-100^{\circ} \mathrm{E}\right)$, East Asia $\left(110-140^{\circ} \mathrm{E}\right)$, Western North

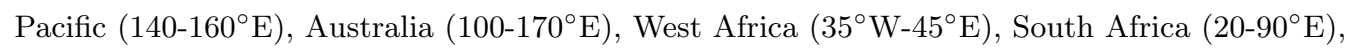
North America $\left(80-120^{\circ} \mathrm{W}\right)$, South America $\left(40-80^{\circ} \mathrm{W}\right)$. Shading shows zonal wind. Light gray contours indicate absolute angular momentum per unit mass, with contours at $\Omega a^{2} \cos ^{2} \phi_{i}$ $\left(\phi_{i}=0^{\circ}, \pm 5^{\circ} \pm 10^{\circ}, \ldots\right)$.

The climatological monsoons show consistency with the aquaplanet results. Awareness of the relevance of the lower-level MSE and upper-level wind structures to the meridional overturning circulation may additionally help in understanding present day variability of the monsoons and model projections of future climate. For example, Hurley and Boos (2013) used reanalysis and observational datasets to explore whether variability in monsoon precipitation could be connected to variability in $\theta_{e b}$. Even removing the signal of variability linked to ENSO, they found that positive precipitation anomalies in the American, African, South Asian and Australian monsoons were associated with enhanced $\theta_{e b}$, consistent with previous findings over West Africa (Eltahir \& Gong, 1996). In addition, variability in $\theta_{e b}$ was found to be due primarily to variability in moisture rather than in temperature, with strong monsoon years associated with enhanced specific humidity near the climatological $\theta_{e b}$ maximum, with temperature anomalies of the opposite sign (see also J. M. Walker, Bordoni, \& Schneider, 2015). This clearly contradicts the classical sea-breeze view of the monsoons, but is consistent with the CQE perspective. Shaw and Voigt (2015) showed that the CQE perspective can help to explain the weak response of the Asian monsoons to global warming seen in climate model projections. Using data from the Atmosphere Model Intercomparison Project (AMIP) experiments, they compared the circulation response to a quadrupling of $\mathrm{CO}_{2}$ with fixed 
SSTs (AMIP4xCO2) with the response to a uniform 4K increase in SST (expected due to a $4 \mathrm{x}$ increase in $\mathrm{CO}_{2}$ ), but with no $\mathrm{CO}_{2}$ increase (AMIP4K). They found that the $\mathrm{CO}_{2}$ forcing led to $\theta_{e b}$ changes that supported a more intense monsoon, but the SST forcing led to opposite $\theta_{e b}$ changes which, they argued, led to a weak net response to an increase in $\mathrm{CO}_{2}$.

The connection of precipitation to lower-level MSE anomalies predicted by CQE is an intuitive focus for understanding monsoon variability and future change. The connection to the upper-level momentum budget has not yet been so comprehensively investigated. However, it has been observed that anomalous upper-level easterlies and westerlies are associated with anomalous upper-level divergence and convergence in monsoon regions in a sense that is consistent with the aquaplanet angular momentum conserving monsoon regime. Enhanced upper-level tropical easterlies, consistent with a higher Rossby number at upper levels (cf. Eq. 4), accompany more intense precipitation over West Africa via enhancement of upper-level divergence and meridional overturning (Nicholson, 2009b). On intraseasonal and interannual timescales over South Asia and West Africa, and interannual timescales over the Western North Pacific, anomalously wet conditions are associated with easterly upper-level zonal wind anomalies, westerly lower-level zonal wind anomalies, and expansion and strengthening of the meridional overturning, with the opposite applying in dry phases (Goswami \& Ajaya Mohan, 2001; Sultan \& Janicot, 2003; J. M. Walker et al., 2015; B. Wang, Wu, \& Lau, 2001). Modulation of the monsoons by anomalous upper-level flow may help in understanding teleconnections between regional monsoons, although more work is needed to explore the mechanisms involved and to ascertain the direction of causality between anomalous upper- and lower-level circulations.

The recent findings summarized in points (4) and (5) above suggest that planetary rotation constrains the maximum latitude that the ITCZ can reach, and the latitude at which the overturning circulation tends to transition from an eddy-driven to an angular momentum conserving regime. The implications for Earth's tropical circulations remain to be explored. However, one could imagine that these latitudinal bounds might provide information on what circulation regime we expect to be associated with a vertical mass flux at a given latitude. Fig. 13 shows the mass fluxes associated with meridional and zonal overturning circulations for May to September and November to March (cf. Schwendike et al., 2014). Gray shading indicates the region between $10-30^{\circ}$ from the Equator. Consistent with the findings of Faulk et al. (2017) for the aquaplanet circulation, the upward mass fluxes associated with the Hadley cell are confined to within $30^{\circ}$ of the Equator. One might further speculate that circulations for which the upward mass flux peaks between $10-30^{\circ}$ from the Equator (Asia, Southern Africa) might bear similarities to the aquaplanet angular momentum conserving regime, while those where ascent remains equatorward of $10^{\circ}$ (Australia, North America, the Atlantic and Pacific ITCZs) might behave more like the aquaplanet eddy-driven regime. Figs. 12 and 13 suggest this idea shows promise, with, for example, the summer overturning circulation over Australia remaining in an eddy-driven regime, while the circulation over areas such as South Asia and Southern Africa becomes more aligned with angular momentum contours. These categorisations of the various flow regimes associated with tropical rainfall could be of use in interpreting the responses of different regions to external forcings.

While the aquaplanet results provide a simple framework for interpreting regional monsoons and their variability, some caveats must be remembered. The regional monsoons are local, stationary wave governed systems, with overturning associated with both meridional and zonal flow (e.g. Fig. 13). Simple symmetric theories do not necessarily extend straightforwardly to these cases, with stationary waves modifying the momentum and energy budgets (Shaw, 2014). Also, in addition to the deep, moist convective overturning circulation, many of the regional monsoons also feature a shallow, dry circulation whose ascent is colocated with the peak in potential temperature (e.g. Hagos 

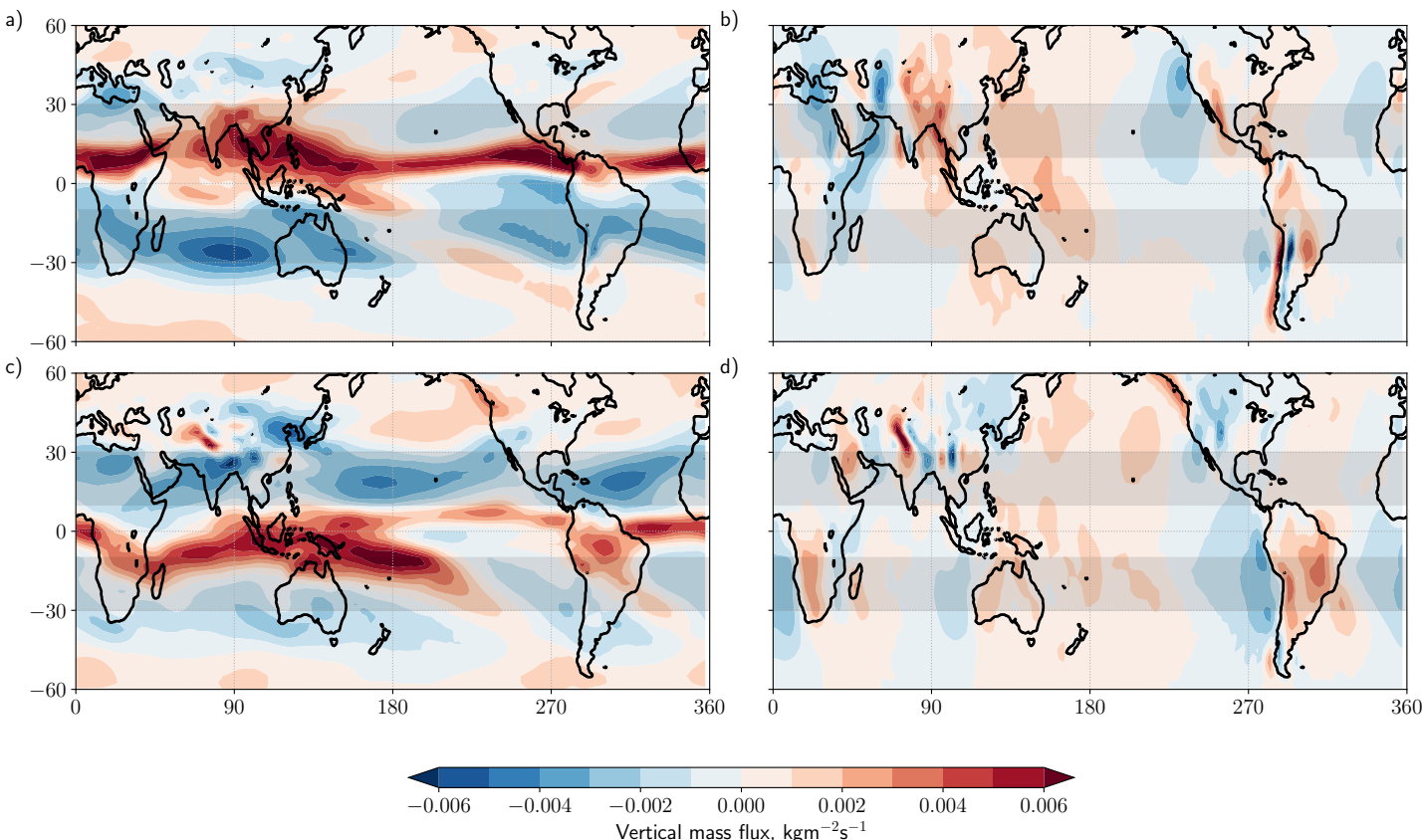

Figure 13. Vertical mass flux at $500 \mathrm{hPa}$, calculated from JRA-55, associated with (a) the divergent meridional circulation and (b) the divergent zonal circulation (cf. Schwendike et al., 2014) in boreal summer, defined as in Fig. 12. (c) and (d) are as (a) and (b) but for austral summer. Gray shading highlights the regions between 10 and $30^{\circ} \mathrm{N} / \mathrm{S}$, see discussion in text.

\& Cook, 2007; Nie et al., 2010; Trenberth, Stepaniak, \& Caron, 2000; C. Zhang, Nolan, Thorncroft, \& Nguyen, 2008); advective drying by this shallow circulation appears to suppress monsoon precipitation (Zhai \& Boos, 2017). Accounting for this behavior requires some adjustments to the CQE assumption (Shekhar \& Boos, 2016).

\subsubsection{Insight from energetic considerations}

As reviewed in Section 2.2., the vertically integrated atmospheric energy budget provides a complementary approach to understanding constraints on tropical rainfall. An elegant finding from applying this in aquaplanets is that the ITCZ approximately follows the EFE, so that changes in zonal mean ITCZ latitude can be linked to changes in net forcing not only in the tropics, but also at higher latitudes (see Section 2.2 and e.g. Bischoff \& Schneider, 2014; Kang et al., 2008). Additionally, the MSE budget allows for a more mechanistic understanding of the local response to such changes. Recent reviews have discussed the energetic perspective of the ITCZ (Schneider et al., 2014) and its application to Earth's monsoons (Biasutti et al., 2018), and so only a brief discussion is given here.

The zonally averaged ITCZ latitude is strongly anticorrelated with the meridional atmospheric energy transport at the Equator, and correlated with the EFE latitude. This relation holds in both observations and under a range of modeled forcing scenarios, although it breaks down where the ITCZ shifts far from the Equator over the seasonal cycle (Adam et al., 2016b; Bischoff \& Schneider, 2014; Donohoe et al., 2013). This relationship helps to explain why the annual mean position of the zonal mean ITCZ is north of the Equator (Marshall et al., 2014). 
Extending this framework to local cases has proved more challenging. Adam, Bischoff, and Schneider (2016a) defined the zonally varying EFE as the latitude at which the meridionally divergent column integrated MSE flux vanishes and has positive meridional gradient. This was found to approximate the seasonal cycle of ITCZ migrations over Africa, Asia and the Atlantic. However, the influence of the Walker cell limited the local EFE's usefulness over the Pacific, and the EFE deviates from the ITCZ in the solstitial seasons that are particularly relevant to the monsoons. Boos and Korty (2016) took this a step further, using the longitudes where the zonally divergent column integrated MSE flux vanishes, and has positive zonal gradient, to define 'Energy Flux Prime Meridians' (EFPMs). Two EFPMs can be identified in each season: over the Bay of Bengal and Gulf of Mexico/Caribbean Sea in boreal summer, and over the Western Pacific and South America in austral summer. They showed that this extended theory gives some basic insight into how localized shifts in precipitation with ENSO relate to anomalous energy transports.

As with the momentum budget framework, while the EFE framework is valuable in explaining some features of the overturning circulation, limitations must be remembered. Relating changes in the latitude of the ITCZ to that of the zonally averaged EFE assumes that the response to forcing is via changes to the meridional overturning circulation, and neglects changes to the gross moist stability. Such changes have been shown to be non-negligible both over the seasonal cycle and in the response to orbital and greenhouse gas forcings (Merlis et al., 2013; Seo, Kang, \& Merlis, 2017; Smyth, Hill, \& Ming, 2018; Wei \& Bordoni, 2018). In addition, Biasutti et al. (2018) noted that while the EFE predicts changes to the ITCZ latitude once the net energy imbalance is known, changes in ocean energy transport, and feedbacks internal to the atmosphere, can result in a net imbalance different to that expected from an imposed external forcing, including orbital forcing (Liu, Battisti, \& Donohoe, 2017).

\subsubsection{Reconciling dynamics and energetics perspectives}

The two perspectives discussed so far in this review have emerged via separate consideration of the momentum and energy budgets, and have yet to be fully connected. Common to both is consideration of processes that can alter the distribution of MSE either in the boundary layer or in a vertically integrated sense, and this might provide a bridge to fill the gaps between these two frameworks.

The local, vertically integrated MSE budget has long been used in explaining the distribution of tropical precipitation. Chou and Neelin (2001) and Chou and Neelin (2003) analysed the column integrated MSE budget in the South American and North American, Asian and African monsoon regions respectively. They identified three key processes governing the MSE distribution and thus determining the extent of tropical rainfall over land: advection of high or low MSE air into the region, soil-moisture feedbacks, and the interaction between the convergence zone and the Rossby wave induced subsidence, which occurs to the west of monsoon heating (the interactive Rodwell-Hoskins mechanism; see Rodwell and Hoskins (2001)). The column integrated MSE budget has also allowed investigation of the mechanisms determining the differing responses of models to intuitively similar forcing scenarios (e.g D'Agostino, Bader, Bordoni, Ferreira, \& Jungclaus, 2019), and the different responses of model variants to the same forcing (e.g Hill, Ming, Held, \& Zhao, 2017; Hill, Ming, \& Zhao, 2018).

Provided CQE holds, so that the tropical atmosphere is near a moist neutral state, the horizontal distribution of column integrated moist static energy will be strongly tied to the distribution of subcloud moist static energy: for example, in Fig, 7 it can be seen that precipitation lies just equatorward of the column integrated MSE. This may allow connections to be made between the constraints arising from the momentum and ener- 
getic frameworks, at least in the zonal mean. However, a unified theory for monsoon circulations remains an outstanding challenge (e.g. Biasutti et al., 2018; Hill, 2019).

\section{Beyond the aquaplanet perspective}

The theories that have emerged from the aquaplanet perspective have begun to prove useful in interpreting the climatology and variability of the tropical monsoon systems on both regional and global scales, particularly where their dynamics show similarities to that of the ITCZ in an aquaplanet. Synthesising idealized modeling work with observational and realistic modeling studies suggests a picture that is consistent with a view of the monsoons and ITCZs as local migrations of the tropical convergence zone:

1. In the zonal mean, the ITCZ latitude is set by energetic constraints (Fig. 9).

2. Locally and seasonally, the convergence zone location appears governed by the MSE distribution, which can be understood via the regional MSE budget (Fig. 11).

3. When the ITCZ is near the Equator, the overturning circulation is strongly influenced by extratropical eddies. Once it is far from the Equator, the cross-equatorial (winter) Hadley cell may approach an angular momentum conserving regime (Fig. $12)$.

4. It may be possible to categorize the dynamics of the various convergence zones as 'monsoons' and 'ITCZs' by their circulation regime, e.g. Figs. 6 and 13, and so deduce where and when extratropical eddies vs. thermal forcing are likely to exert a stronger or weaker control over regional rainfall.

5. Regional variability in monsoon precipitation on interannual timescales (and perhaps subseasonal timescales) appears related to local variations in MSE which, where CQE applies, is connected to variations in the Hadley circulation.

6. Global variability in the latitude of the zonal mean convergence zone on interdecadal and longer timescales is driven by variations in the hemispheric energy budgets, with consequences for regional monsoon rainfall.

However, there are important influences on the regional monsoons and ITCZs that are not well accounted for by the above, in particular, the roles of zonal asymmetries and transient activity in the tropics.

\subsection{Asymmetries in the boundary conditions}

Zonal asymmetries, such as land-sea contrast, orography, and the ocean circulation, introduce complications unaccounted for by the simple aquaplanet framework. One key feature of the regional monsoons that cannot be captured by the symmetric picture is the presence of the subtropical frontal zones that occur on the eastern side of the monsoon lows: the Meiyu-Baiu frontal zone, the South Pacific Convergence Zone (SPCZ), the South Atlantic Convergence Zone, and the South Indian Convergence Zone, which extends off the southeast coast of Southern Africa (Cook, 2000; Kodama, 1992). In particular, the monsoons of East Asia and South America require us to step beyond the perspective of angular momentum conserving monsoons and eddy-driven ITCZs.

\subsubsection{East Asia - a frontal monsoon}

While the South Asian monsoon fits well with the theoretical paradigm emerging from idealized work, the circulation over East Asia behaves very differently. Here, wind reversal is predominantly meridional, and monsoon precipitation extends north into the subtropics (Fig. 10). Summer precipitation is concentrated into the Meiyu-Baiu front, a rainband which forms on the northern boundary of the high MSE air mass centered over South Asia and the Bay of Bengal (Ding \& Chan, 2005, and references therein). This front migrates northward in steps over the summer season, as detailed in Section 3.1. 
Unlike in tropical monsoon regions, in the Meiyu-Baiu region the net energy input into the atmospheric column is negative. Vertical upward motion and convection in the front (with associated energy export) require MSE convergence, which is provided by horizontal advection, with interactions between the Tibetan Plateau and the westerly jet playing a key role (Chen \& Bordoni, 2014; J. Chiang, Wu, Kong, \& Battisti, 2020; Molnar, Boos, \& Battisti, 2010; Sampe \& Xie, 2010). Comparing the monsoon season precipitation in this region in numerical experiments with and without the Tibetan Plateau indicates that, when the plateau is removed, precipitation is weakened and is no longer focused into the front (Chen \& Bordoni, 2014). Analysis of the MSE budget of these simulations suggests that the plateau chiefly reinforces convergence into the Meiyu-Baiu region by strengthening the southerly stationary eddy downstream. The subtropical westerly jet off the eastern flank of the Plateau additionally appears to act as an anchor for transient precipitating weather systems, focussing precipitation along the front (Molnar et al., 2010; Sampe \& Xie, 2010).

Over the summer season, the East Asian Summer monsoon features two abrupt northward jumps of the precipitation, with three stationary periods (Ding \& Chan, 2005). This intraseasonal evolution of the monsoon has also been suggested to relate to interactions between the plateau and westerly jet, with the migration of westerlies from the south of the plateau to the north causing the first abrupt jump and the development of Meiyu, and the northward migration of westerlies away from the plateau causing the second (Kong \& Chiang, 2020; Molnar et al., 2010). A series of recent papers has examined implications of this interaction for interpretation of changes to the East Asian summer monsoon over the paleoclimate record (J. C. H. Chiang et al., 2015) and the Holocene (Kong, Swenson, \& Chiang, 2017), and for interannual variability of the East Asian summer monsoon (J. C. H. Chiang, Swenson, \& Kong, 2017), with the hypothesis appearing able to explain all cases.

\subsubsection{South America - a zonal monsoon}

Similarities have been noted between the South American and East Asian monsoons; however, studies indicate that diabatic heating over land is most important in generating the upper-level monsoon anticyclone over South America (Lenters \& Cook, 1997). One important difference is that the Andes form a narrow, meridionally oriented barrier from the tropics to subtropics. This acts to divert the easterly flow from the Atlantic to the south, concentrating it into the South American Low Level Jet (Byerle \& Paegle, 2002; Campetella \& Vera, 2002) and inducing adiabatic ascent (Rodwell \& Hoskins, 2001). In austral summer, the result is a zonally convergent mass flux of similar magnitude to the meridionally convergent component (Fig. 13), which extends the summer precipitation southward.

\subsubsection{The Pacific and Atlantic ITCZs}

Energy and momentum considerations are useful in understanding the behavior of the zonal mean ITCZ, especially in an aquaplanet where the boundary conditions are symmetric. However, to understand the regional positions and seasonal cycle of the ITCZ, the effects of zonal asymmetries must also be considered.

Except for in the far western tropical Atlantic where the ITCZ dips slightly south of the Equator in March and April, the ITCZ is north of the Equator year-round in the Atlantic and Pacific (Fig. 8). This appears to be due to the land monsoon heating and the geometrical asymmetry in tropical Africa and South America (Rodwell \& Hoskins, 2001). Specifically, the austral summer monsoon in southern Africa forces subsidence to the west and causes a subtropical high to build over the southern subtropical tropical Atlantic, increasing the southeasterly trade winds which act to cool the ocean by enhanced turbulent energy fluxes. Together, the subsidence and cool water suppress convection 
south of the Equator in the austral summer and fall. In addition, in boreal summer the north African monsoon forces a strong local Hadley circulation that also causes subsidence in the sub-tropical south Atlantic which supports the formation of stratus clouds that further cool the ocean during austral winter. Hence, the ITCZ does not transit into the Southern Hemisphere in austral summer.

Subsidence is also seen off the west coast of South America in austral summer. This descent can be attributed to a range of factors. SSTs over the western coast of South America are cooler due to coastal upwelling (e.g. Takahashi, 2005), but this cooling is largely confined to within $50 \mathrm{~km}$ of the coast. Equatorward flow is generated to the west in response to heating over the Amazon (Rodwell \& Hoskins, 2001), which descends adiabatically. The extratropical mid-level westerlies incident on the Andes are also diverted equatorward, contributing to further descent and evaporative cooling of the ocean by the dry subsiding air (e.g. Fig. 8; Rodwell \& Hoskins, 2001; Takahashi \& Battisti, 2007). The large-scale descent causes an inversion to form that allows for the development of largescale stratus clouds that cool the ocean for thousands of kilometers offshore, which suppresses convection over the eastern Pacific, particularly in austral summer. The largescale descent forced by the Andes causes the Pacific ITCZ to be located exceptionally far north of the Equator throughout the year (Maroon, Frierson, \& Battisti, 2015; Takahashi \& Battisti, 2007). It may also partially account for the large seasonal contrast in precipitation in the North American monsoon, which involves an eastward extension of the Pacific ITCZ (Figs. 1 and 13).

\subsection{The role of transients}

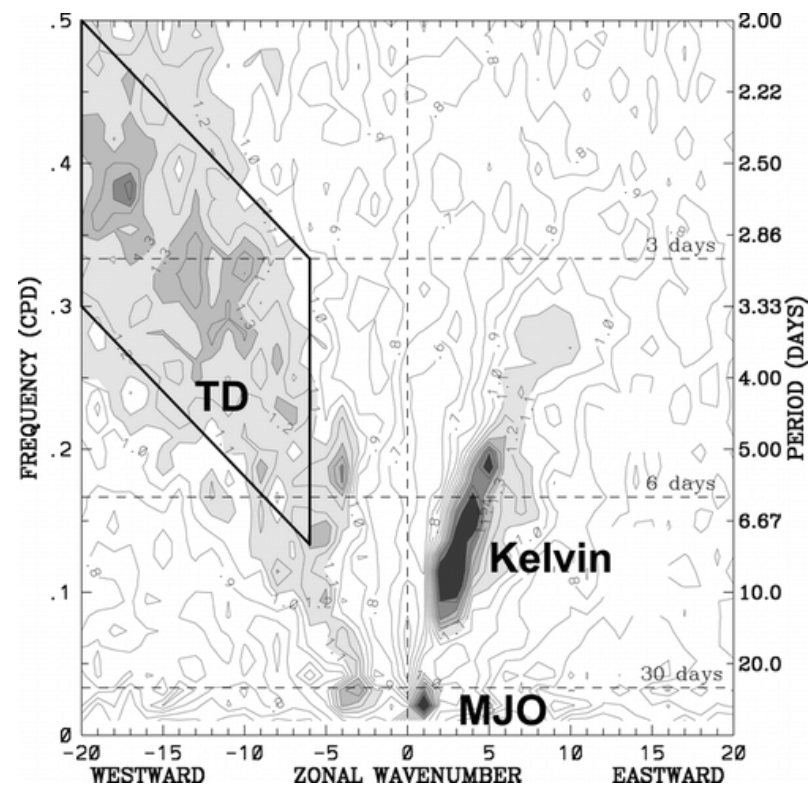

Figure 14. Wavenumber-frequency power spectrum of the symmetric component of OLR for June-August $1979-2003$, averaged from $15^{\circ} \mathrm{N}$ to $15^{\circ} \mathrm{S}$, plotted as the ratio of the raw OLR spectrum against a smooth red noise background (see Wheeler \& Kiladis, 1999, for details). Contour interval is 0.1 . Shading begins at 1.1 , where the signal is statistically significant at approximately the $95 \%$ level. Peaks associated with the MJO, tropical depressions, and Kelvin waves are identified. Taken from Kiladis et al. (2006). (C)American Meteorological Society. Used with permission. 
Even in an aquaplanet, tropical rainfall does not occur in a zonally uniform, continuously raining band. For simplicity, theoretical studies like those discussed in Section 2 tend to consider time and zonal means and neglect transient activity except for its contribution to the momentum and energy budgets via eddy fluxes from the extratropics. However, many types of transient activity occur in the tropics. Wheeler and Kiladis (1999) produced wavenumber-frequency spectra of tropical outgoing longwave radiation (OLR), which is used as a proxy for deep convection, and showed that the spectral peaks that emerge are similar to wave modes of the shallow water equations on the beta plane (Matsuno, 1966), providing clear evidence for a strong influence of convectively coupled waves on tropical precipitation.

Fig. 14 shows a Wheeler-Kiladis wavenumber-frequency spectrum for Northern Hemisphere summer (Kiladis et al., 2006). In this season, the spectrum of the symmetric component of tropical OLR exhibits three dominant peaks: eastward propagating waves associated with the Madden-Julian Oscillation (MJO) and Kelvin waves, and westward propagating waves classed as tropical depressions. Here we focus on the organisation of precipitation by these features, followed by a discussion of the transients observed in the ITCZs. $^{7}$

\subsubsection{Intraseasonal timescales}

Fig. 14 shows intense activity associated with low wavenumbers and a period of 30-60 days. This has been shown to correspond to the MJO; a convectively coupled, largescale equatorially trapped wave that propagates slowly eastward from the east coast of Africa to the western-central Pacific, whereafter it continues eastward as a Kelvin wave (Madden \& Julian, 1971, 1972; C. Zhang, 2005, and references therein). The structure of the MJO is illustrated in Fig. 15. The oscillation has strong influences on tropical rainfall, particularly in the Indo-Pacific region (see examples below), but the precise mechanism responsible remains a topic of ongoing research.

\section{The Madden Julian Oscillation and the tropical Indian Ocean 'ITCZ'}

Precipitation in the Indian Ocean sector in austral summer is found between $10^{\circ} \mathrm{N}$ and $15^{\circ} \mathrm{S}$, but is concentrated slightly south of the Equator. It can be seen from Fig. 8 that, unlike the Atlantic and Pacific ITCZs, precipitation in the Indian Ocean is not organized into a narrow zonal band, and it is due to a different physics than is described in Section 2.1.3 (the zonal asymmetry in SST is insufficient to drive a symmetrically unstable flow). Estimates show that between 30 and $40 \%$ of the annual precipitation in the Indian Ocean and Maritime continent $\left(10^{\circ} \mathrm{N}\right.$ and $10^{\circ} \mathrm{S}, 70^{\circ} \mathrm{E}$ and $\left.150^{\circ} \mathrm{E}\right)$ is associated with the MJO (Kerns \& Chen, 2020).

\section{Intraseasonal variability in the Indo-Pacific}

In the Indo-Pacific region, the MJO features trailing Rossby waves with enhanced shear zones that angle polewards and westwards from the precipitation center near the Equator and support precipitation. Hence, along a fixed longitude, bands of precipitation appear to propagate poleward from the Equator to about $20^{\circ} \mathrm{N}$ over India as the MJO propagates eastward over the maritime continent (Hartmann \& Michelsen, 1989; Wallace, Battisti, Thompson, \& Hartmann, 2020).

In boreal summer, in addition to the MJO, the climate in this region appears to be modulated by propagating 'Boreal Summer Intraseasonal Oscillations' (BSISO), observed to have dominant timescales of 10-20 and 30-60 days, and to propagate northward

\footnotetext{
${ }^{7}$ A more detailed discussion of equatorial waves can be found in Roundy and Frank (2004), who develop a climatology, and in a review of the subject by Kiladis, Wheeler, Haertel, Straub, and Roundy (2009).
} 


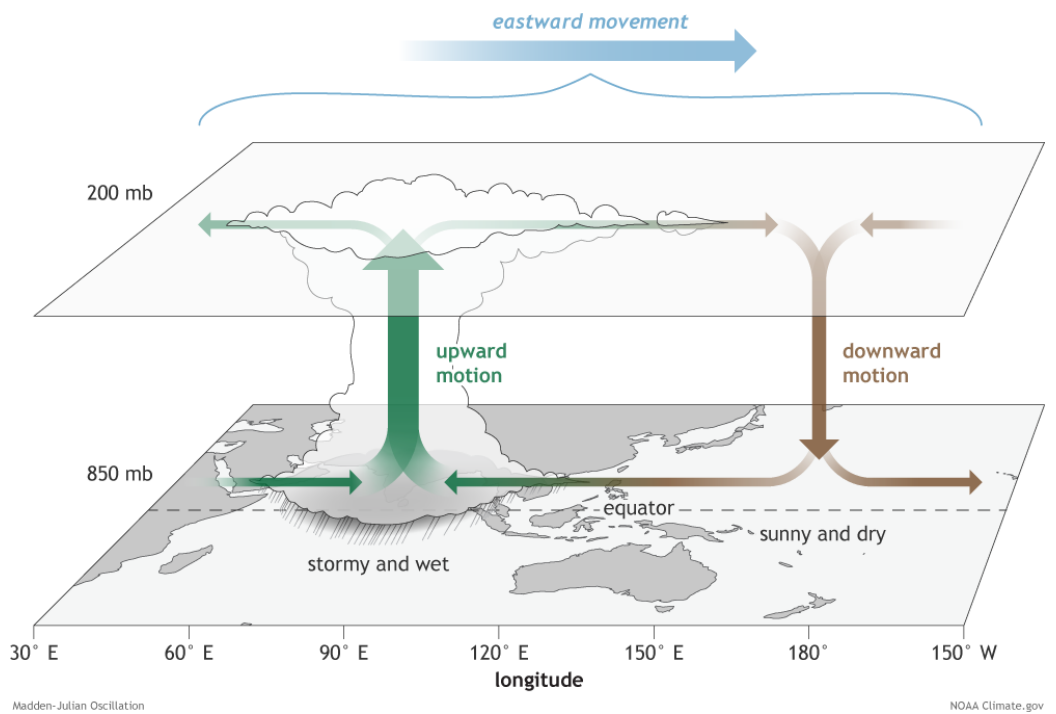

Figure 15. The surface and upper-atmosphere structure of the MJO for a period when the enhanced convective phase is centered across the Indian Ocean and the suppressed convective phase is centered over the west-central Pacific Ocean. Horizontal arrows pointing left represent wind departures from average that are easterly, and arrows pointing right represent wind departures from average that are westerly. The entire system shifts eastward over time. From NOAA Climate.gov (Gottschalck, 2014), drawing by Fiona Martin.

over the continent (Annamalai \& Slingo, 2001; Goswami \& Ajaya Mohan, 2001; Hartmann \& Michelsen, 1989; Lee et al., 2013). These oscillations modulate the active and break phases of the Indian monsoon, with the tropical convergence zone and associated Hadley circulation oscillating between an off-equatorial 'monsoon' location, and a near equatorial 'ITCZ' location (e.g. Annamalai \& Slingo, 2001; Goswami \& Ajaya Mohan, 2001; D. R. Sikka \& Gadgil, 1980). Like the MJO, the propagation mechanism and precise drivers of the BSISOs remain unclear, and are the subject of ongoing research. Some authors argue that the BSISOs are distinct from the MJO (e.g Lee et al., 2013; B. Wang \& Xie, 1997), while others identify them as associated with the MJO (e.g. Hartmann \& Michelsen, 1989; Jiang, Adames, Zhao, Waliser, \& Maloney, 2018).

\subsubsection{Monsoon lows, depressions $\&$ easterly waves}

In addition to the influence of oscillations on intraseasonal timescales, regional monsoon precipitation has long been observed to be organized by westward propagating synopticscale low-pressure systems, including African Easterly Waves, observed over West Africa (e.g. Burpee, 1974; Reed, Norquist, \& Recker, 1977), and monsoon depressions, observed in the Indian and Australian monsoon regions (e.g. Godbole, 1977; Mooley, 1973; D. Sikka, 1978). Hurley and Boos (2015) produced a global climatology of monsoon lows. They found that the behavior over India, the western Pacific and northern Australia showed strong similarities, with a deep warm-over-cold core (e.g. Fig. 16a). A second class of systems was seen over West Africa and western Australia, with a shallower warm core (e.g. Fig. 16b). They estimated that monsoon low-pressure systems are responsible for at least $40 \%$ of precipitation in monsoon regions (Fig. 16c,d).

Fig. 16 confirms that the monsoon depressions observed over South Asia are distinct from the easterly waves observed over Africa. The mechanisms for both are still 

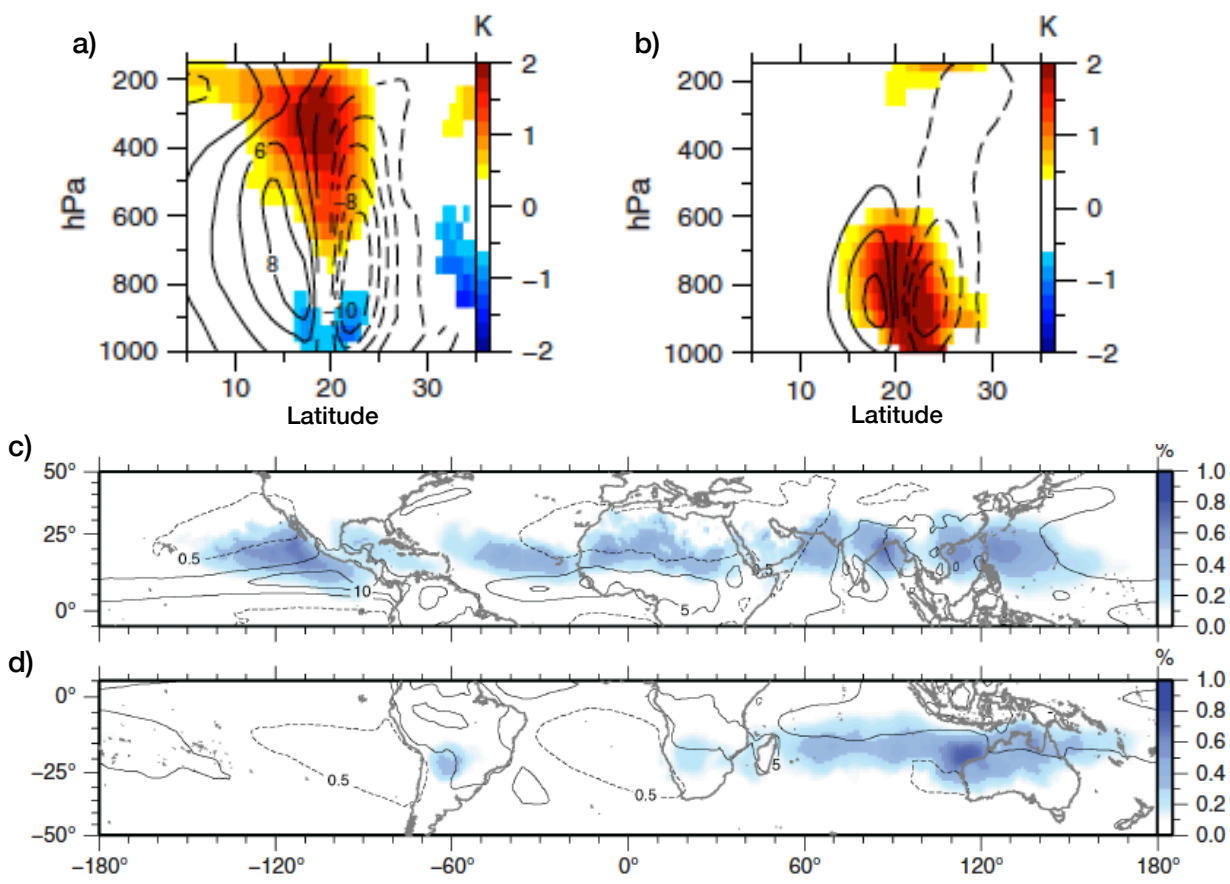

Figure 16. Northern Hemisphere summer (May-September) regional composites of monsoon depressions from ERA-Interim (1979-2012). Composite vertical sections through the storm center of potential temperature ( $\mathrm{K}$, shading) and zonal wind $\left(\mathrm{ms}^{-1}\right.$, contours) anomalies are shown for (a) India and (b) West Africa. Dashed contours are negative. Values are shaded or contoured where a t-test indicates significance at the $5 \%$ level. (c) and (d) show the fraction (shading) of total summer precipitation that can be attributed to monsoon lows and monsoon depressions in May-September and November-March respectively. Shading indicates the ratio of precipitation within $500 \mathrm{~km}$ of all tracked lows and depressions to the total summer precipitation. Contours reflect the summer climatological precipitation rate. Dashed contours surround dry regions, where precipitation is on average less than $0.5 \mathrm{~mm} /$ day. Solid contours indicate wet regions, where precipitation is greater than $5 \mathrm{~mm} /$ day $(5 \mathrm{~mm} /$ day contour interval). Adapted from Figs. 9 and 12 of Hurley and Boos (2015). (c)2014 Royal Meteorological Society. Used with permission.

being investigated. Recent work indicates that monsoon depressions form over South Asia from moist barotropic instability due to the meridional shear of the monsoon trough, and are intensified by latent heating (Diaz \& Boos, 2019a, 2019b). The occurrence of depressions can be modulated by variations in the background flow. For example, ENSO causes large-scale changes in the summertime environment that has a modest statistical effect on the strength of synoptic scale tropical depressions that propagate from the Bay of Bengal to the northwest over India (Hunt, Turner, Inness, Parker, \& Levine, 2016), with La Niña (El Niño) conditions favoring tropical depressions with enhanced (weakened) precipitation.

Over Africa and the Atlantic, strong surface heating of the Sahara in summer forces a monsoon circulation that is barotropically and baroclinically unstable (Burpee, 1972; M.-L. C. Wu, Reale, Schubert, Suarez, \& Thorncroft, 2012, and references therein). Instabilities in the flow give rise to African Easterly Waves. The precise dynamics governing the amplification, propagation and variability of these waves remain unclear. Seasons with strong African Easterly Wave activity have been found to be associated with a strong upper level easterly jet (Nicholson, 2009a) and an enhancement of other equa- 
torial waves, specifically Rossby and westward-moving mixed Rossby-gravity wave modes (Y.-M. Cheng, Thorncroft, \& Kiladis, 2019; Yang, Methven, Woolnough, Hodges, \& Hoskins, 2018).

\subsubsection{Transients in the ITCZ}

Easterly waves and other organized synoptic disturbances are important contributors to the ITCZs in the tropical Atlantic and Pacific. An upper bound on their contribution to ITCZ precipitation can be estimated by assuming that all precipitation events lasting more than 24 hours are related to organized synoptic disturbances, in which case the fraction of the total precipitation in the Atlantic and Pacific ITCZs that is due to large-scale organized waves is about $40 \%$ (White, Battisti, \& Skok, 2017). Alternatively, about half of the total precipitation in these ITCZs is in the form of stratiform precipitation (Schumacher \& Houze Jr, 2003), which is overwhelmingly in the form of long-lived mesoscale convective systems (Houze Jr, 2018).

African Easterly Waves propagate westward into the Atlantic Ocean and are the primary precursors of tropical cyclones in the Atlantic. The associated rainfall contributes to the summer precipitation in the Atlantic ITCZ. Easterly waves are also found in the tropical east and central Pacific, although the dynamics of these systems is different from their Atlantic counterparts. Many easterly waves in the Pacific are Mixed Rossby-Gravity waves: antisymmetric equatorially trapped waves with low pressure centered on $5-10^{\circ}$ latitude (Kiladis et al., 2009; Matsuno, 1966). Friction acts to cause convergence in the low pressure centers and in the Northern Hemisphere this leads to moisture convergence and precipitation (Holton, Wallace, \& Young, 1971; Liebmann \& Hendon, 1990) (the low pressure center in the Southern Hemisphere does not feature precipitation because the water is cold and there is strong subsidence). Other convectively coupled equatorial waves that contribute to the ITCZ in the central Pacific include Kelvin waves (in which convection is not symmetric about the Equator) and inertio-gravity waves (Kiladis et al., 2009).

\section{Conclusions and outlook}

This article has reviewed the theory of monsoons that has resulted in large part from idealized models and discussed the behavior of Earth's monsoons in light of the theory. While the regional monsoons have a diverse range of individual features, they also have much in common, including enhancement of cross-equatorial and westerly flow in the summer season, rapid onset, and development in an off-equatorial direction. In addition, regional monsoons often covary as components of a global monsoon, both under changes to orbital forcing, and to internal variations in the climate state such as ENSO (P. X. Wang et al., 2014). The theoretical considerations outlined in Section 2 are starting to provide explanations for these behaviors, as presented in Section 3, but many open problems remain in connecting theoretical ideas to observations (Section 4). We conclude the review by discussing these successes and challenges.

\subsection{Successes}

Insight from theory has caused a shift in the understanding of monsoon dynamics - from that of primarily land-sea contrast driven, sea-breeze like circulations, to localized variations of the convergence zone and overturning circulations, strongly governed by the momentum and energy budgets.

The momentum budget, Eq. 4, indicates three classes of solution for the Hadley circulation: a 'radiative-convective equilibrium' regime, $v=\omega=0$; an 'angular momentum conserving' regime, in which the Rossby number Ro approaches 1 and eddies have a negligible effect; and an 'eddy-driven' regime, where $R o$ is much less than 1 and 
eddies strongly influence the overturning circulation. Our understanding of monsoon dynamics has been greatly advanced by considering the transitions between these regimes, and the controls on the latitude of the ascending branch of the circulation.

Constraints on the zonal mean ITCZ latitude have been identified by considering the energetics of the circulation, in addition to the momentum budget. If the atmosphere is in CQE then, for an angular momentum conserving overturning circulation, the ITCZ is expected to lie just equatorward of the peak in subcloud moist static energy (see Privé and Plumb (2007a, 2007b), and Section 2.1). The subcloud distribution of MSE therefore strongly constrains the circulation. A related energetic constraint is obtained from considering the vertically integrated MSE budget (Eq. 10). The latitude of the EFE has been found to be approximately colocated with the ITCZ latitude, allowing the zonal mean ITCZ location to be related to the meridional cross-equatorial energy flux and net energy input at the Equator (e.g. Bischoff \& Schneider, 2016).

The latitude of the convergence zone is also related to the dynamics that govern the Hadley circulation. It has been demonstrated in aquaplanets that when the convergence zone is on or near the Equator the circulation is more eddy-driven (i.e., an ITCZ), while when the convergence zone is far from the Equator the circulation is near angular momentum conserving (Bordoni \& Schneider, 2008, 2010; Schneider \& Bordoni, 2008). These 'ITCZ' and 'monsoon' regimes are illustrated schematically in Figs. 6a and b respectively. In aquaplanet simulations with a low thermal inertia surface, similar to land, a fast transition between these two regimes is observed, with the zonal mean ITCZ jumping off the Equator into the summer hemisphere at the start of the summer season. This fast transition is mediated by two feedbacks. Firstly, as the ITCZ shifts off the Equator and the Hadley circulation becomes cross equatorial, the lower branch of the Hadley cell advects cooler, drier air up the meridional MSE gradient. Combined with the continued diabatic warming of the summer hemisphere by the insolation, this has the effect of pushing the MSE peak poleward and so shifting the convergence zone farther off the Equator (Fig. 7). Secondly, as a result of angular momentum conservation, the equatorward upper-level meridional flow gives rise to upper-level easterlies. These easterlies suppress propagation of extratropical eddies into the low latitudes (Charney \& Drazin, 1961) and help to kick the Hadley cell into the angular momentum conserving regime, so that the meridional overturning is strongly responsive to the thermal forcing and strengthens and broadens further.

Recent results suggest that in an aquaplanet, the transition between an eddy-driven and angular momentum conserving Hadley circulation occurs when the ITCZ migrates to $\sim 7^{\circ}$, regardless of slab ocean characteristics (Geen et al., 2019). In this review, we have argued that the former case is relevant to the dynamics of the observed ITCZs, while the latter is appropriate for understanding the monsoon circulations. Another recent strand of research has explored the maximum limits on the migrations of the ITCZ away from the Equator: in aquaplanets, the convergence zone does not migrate more than $30^{\circ}$ poleward, even when the MSE maximum is at the poles (Faulk et al., 2017). Current work (Hill et al., 2019; Singh, 2019) is exploring this poleward limit of monsoons using constraints relating the Hadley circulation regime to the curvature of the subcloud equivalent potential temperature.

Analysis of observations has demonstrated that the South Asian, Australian and African monsoons show behavior similar to that described by the above theoretical work. In these monsoons, the peak precipitation is located just equatorward of the peak in subcloud MSE (Nie et al., 2010) and the convergence zones migrate in line with the EFE (Adam et al., 2016b; Boos \& Korty, 2016). In monsoons where the ascending branch migrates far from the Equator, such as the South Asian and South African monsoons, the summertime overturning circulation becomes aligned with angular momentum contours, suggesting a strongly thermally driven cross-equatorial flow regime (e.g. Bordoni \& Schneider, 2008; J. M. Walker \& Bordoni, 2016). In addition, while a more thorough analy- 
sis is needed, we note from Fig. 13 that a change from an eddy-driven ('ITCZ') to an angular momentum conserving ('monsoon') overturning regime indeed appears to occur when ascent moves poleward of $\sim 10^{\circ}$ (Geen et al., 2019). For Earth's planetary rotation and insolation characteristics, the tropics, and the tropical overturning circulations, are confined within $\sim 30^{\circ}$ of the Equator (Faulk et al., 2017). Current work is exploring conditions under which monsoon-like, cross-equatorial cell can extend further away from the Equator and what sets their poleward boundary under these more exotic conditions (Hill et al., 2019; Singh, 2019).

Awareness of these mechanisms can help motivate work investigating sources of interannual variability, and the response to external forcings, with one clear goal being a better mechanistic understanding of model projections forced by future warming scenarios. On this front, some success has already been achieved. For example, interannual variability in monsoon precipitation has been found to be correlated to variability in subcloud MSE (Hurley \& Boos, 2013). Migrations of the zonal mean ITCZ under historical forcings have been examined in relation to migrations of the EFE (Donohoe et al., 2013). Interannual variability of the West African monsoon has been connected to the strength of the upper-level easterly jet (Nicholson, 2009b). The weak changes to the Asian monsoon in simulations of future climate appear to be explained by opposing responses to increased $\mathrm{CO}_{2}$ levels and surface warming (Shaw \& Voigt, 2015). Further exploration of the observations, informed by theory, could prove fruitful for improved understanding of model biases, or for identifying sources of seasonal predictability.

\subsection{Challenges}

Constraints on the zonal and time mean ITCZ and overturning circulation are beginning to emerge from theory and have now been successfully applied to aquaplanets and to some features of the observations. This represents a significant step in our understanding of the tropical circulation. However, asymmetries that arise from land-sea contrast and orography introduce a zoo of additional complications that these simple theories do not account for, and some care must therefore be taken in applying aquaplanet theories to reality. For example, while the monsoon circulation in an aquaplanet is characterized by an angular momentum conserving Hadley circulation, stationary waves can be important when zonal asymmetries are included in the boundary conditions (Shaw, 2014). However, as we show here in Fig. 12, in individual monsoon sectors (South Asia, Africa and Australia) advection of momentum by the mean circulation causes the overturning circulation to approach an angular momentum conserving state.

As discussed in Section 4, the pattern of precipitation in the South American monsoon and the intensity of the East Asian monsoon in particular are strongly influenced by orography. The interaction of the westerly jet with the orography of Tibet generates a stationary wave downstream over East Asia that gives rise to the Meiyu front and governs the duration of the stages of the East Asian summer monsoon. In South America, the Andes divert the tropical easterly and subtropical westerly flow, resulting in strong equatorward descending flow to the west of the mountains, and poleward ascending flow to the east. In austral summer, the South American low-level jet develops to the east of the Andes and extends the South American monsoon flow southward. This results in precipitation that is displaced far from the Equator, but without the formation of an angular momentum conserving Hadley cell of the kind seen in aquaplanets. The descending flow to the west of the Andes suppresses precipitation year-round off the coast of South and Central America, over the East Pacific and helps to push the ITCZ north of the Equator year round. Overall, we conclude that aquaplanet theories do not appear applicable to the American monsoons, or to the East Asian monsoon. Hierarchical modeling work, where complexity is introduced in a progressive way, might be the path forward to make conceptual progress in the understanding of similarities and differences between individual monsoon systems. Initial steps on this hierarchy are already being taken, by 
introducing continents into idealized models (J. Chiang et al., 2020; Geen et al., 2018; Hui \& Bordoni, in prep.; Zhou \& Xie, 2018), or removing orography from more complete models (Baldwin, Vecchi, \& Bordoni, 2019; Boos \& Kuang, 2010; Wei \& Bordoni, 2016).

Transients make a non-negligible contribution to precipitation in the regional monsoons and ITCZs. These phenomena are not accounted for in the theoretical framework reviewed in Section 2. In some cases, parallel ideas exist, which should be possible to synthesize. For example, as discussed in Section 4, monsoon onset over South Asia and the South China Sea has been suggested to relate to the arrival of the moist phase of a transient Intraseasonal Oscillation (ISO), with active and break phases throughout the season then arising due to further ISOs (e.g. Lee et al., 2013). Aquaplanet based modeling work has instead led to development of a zonal- and climatological-mean view of monsoon onset as a regime change of the Hadley circulation (see Section 2.1 and Bordoni \& Schneider, 2008; Schneider \& Bordoni, 2008). These ideas appear tantalisingly reconcilable; for example the arrival of an ISO might act as the trigger for the regime change of the circulation, and the active and break phases of the Indian monsoon could be connected to intraseasonal changes in Hadley cell regime. However, evidence for this has yet to be examined in idealized models or in reanalysis. The MSE budget has been used to investigate the propagation of the MJO (Andersen \& Kuang, 2012; Jiang et al., 2018; Sobel \& Maloney, 2013), and may provide a way to bridge these two perspectives.

Perhaps the greatest challenge for theory and modeling is to determine how the monsoon systems will change in future climates. The current consensus from CMIP5 models is that the precipitation in the global monsoon is likely to increase under anthropogenic forcings, though the monsoon circulation is likely to weaken (Christensen et al., 2013). However, there is a significant spread in model projections (e.g. Seth et al., 2019, and references therein), and models show varying degrees of skill in capturing the presentday climatology of the monsoon and its variability (e.g Jourdain et al., 2013; Roehrig, Bouniol, Guichard, Hourdin, \& Redelsperger, 2013; Sperber et al., 2013). As discussed in Section 3.2, future predictability depends on direct and indirect responses to radiative forcing, which may oppose one another (Shaw \& Voigt, 2015). However, we suggest that a more complete understanding of the constraints on the monsoons will provide opportunities to identify model biases affecting their simulation of present climate, and may allow future projections to be better constrained.

\section{Glossary}

AMIP Atmospheric Model Intercomparison Project. A project comparing the behaviors of atmospheric general circulation models forced by realistic sea surface temperatures and sea ice.

BSISO Boreal Summer Intraseasonal Oscillation. Describes the dominant modes of tropical intraseasonal variability over Asia during boreal summer.

CQE Convective Quasi-Equilibrium. A theoretical framework for the tropical atmosphere that assumes the atmospheric lapse rate is maintained close to a moist adiabat due to the occurrence frequent, intense moist convection. See discussion in Section 2.1.

Earth System model A comprehensive model of the Earth System, simulating the fluid motions and thermodynamics of the atmosphere and ocean, as well as interactions with ice, the land surface and vegetation, and ocean biogeochemistry.

EFE Energy Flux Equator. The latitude at which the vertically integrated MSE flux is zero.

EFPM Energy Flux Prime Meridian. Defined as the longitudes at which the zonally divergent column integrated MSE flux vanishes and has positive zonal gradient.

ENSO The El Niño-Southern Oscillation. A recurring climate pattern involving changes to the temperature of the waters in the Pacific Ocean. El Niño (La Niña) phases 
are associated with warmer (cooler) than usual SSTs in the central and eastern tropical Pacific Ocean.

GCM Global Circulation Model. A numerical model for the circulation of the atmosphere and/or ocean.

Heinrich event A natural phenomenon featuring the collapse of Northern Hemisphere ice shelves and consequently the release of large numbers of icebergs.

Idealized model A model in which only some elements of the Earth System are included to allow testing of theories in a more conceptually simple and computationally affordable framework.

ISO Intra-seasonal Oscillation

ITCZ Intertropical Convergence Zone. The upward branch of the overturning circulation that is driven primarily by eddy momentum fluxes and located with $\sim 10^{\circ}$ of the Equator, and characterized by low-level moisture convergence and precipitation.

Monsoon The rainy summer season of a tropical region, in which tropical precipitation extends far from the Equator, the low-level prevailing wind changes direction or strength, and the overturning circulation approaches the angular momentum conserving (eddy-less) limit.

MJO Madden-Julian Oscillation

MSE Moist static energy, defined in Eq. 9.

RCE Radiative-convective equilibrium. Describes the balance between the radiative cooling of the atmosphere and the heating via latent heat release resulting from convection.

Sea breeze A wind that blows from a large body of water onto a landmass due to differences in surface temperature, and consequently air pressure, between the land and water.

SPCZ South Pacific Convergence Zone. The band convergence observed over the SouthWest Pacific, e.g. Fig. 1e.

SST Sea Surface Temperature

\section{Acknowledgments}

RG was supported by the UK-China Research and Innovation Partnership Fund, through the Met Office Climate Science for Service Partnership (CSSP) China, as part of the Newton Fund. SB and KLH acknowledge support from the Caltech Terrestrial Hazard Observation and Reporting (THOR) center and the Caltech GPS Discovery Fund. DSB was funded by the Tamaki Foundation. The research materials supporting this publication can be accessed by contacting Ruth Geen (rg419@exeter.ac.uk).

\section{References}

Adam, O., Bischoff, T., \& Schneider, T. $\quad$ (2016a). Seasonal and interannual variations of the energy flux equator and ITCZ. Part II: Zonally varying shifts of the ITCZ. Journal of Climate, 29(20), 7281-7293. doi: 10.1175/JCLI-D-15-0710.1

Adam, O., Bischoff, T., \& Schneider, T. (2016b). Seasonal and interannual variations of the energy flux equator and ITCZ. Part I: Zonally averaged ITCZ position. Journal of Climate, 29(9), 3219-3230. doi: 10.1175/JCLI-D-15-0512.1

Adams, D. K., \& Comrie, A. C. (1997). The North American Monsoon. Bulletin of the American Meteorological Society, 78(10), 2197-2214. doi: 10.1175/1520 -0477(1997)078<2197:TNAM $\rangle 2.0 . C O ; 2$

An, Z., Guoxiong, W., Jianping, L., Youbin, S., Yimin, L., Weijian, Z., ... Juan, F. (2015). Global Monsoon Dynamics and Climate Change. Annual 
Review of Earth and Planetary Sciences, 43(1), 29-77.

doi: $10.1146 /$ annurev-earth-060313-054623

Ananthakrishnan, R., \& Soman, M. K. (1988). The Onset of the Southwest Monsoon over Kerala: 1901-1980. Journal of Climatology, 8, 283-296. doi: 10 $.1002 /$ joc. 3370080305

Andersen, J. A., \& Kuang, Z. (2012). Moist Static Energy Budget of MJO-like Disturbances in the Atmosphere of a Zonally Symmetric Aquaplanet. Journal of Climate, 25(8), 2782-2804. Retrieved from https://doi.org/10.1175/JCLI-D -11-00168.1 doi: 10.1175/JCLI-D-11-00168.1

Annamalai, H., \& Slingo, J. M. (2001). Active/break cycles: Diagnosis of the intraseasonal variability of the Asian Summer Monsoon. Climate Dynamics, 18(1), 85-102. Retrieved from https://doi.org/10.1007/s003820100161 doi: $10.1007 / \mathrm{s} 003820100161$

Arakawa, A., \& Schubert, W. H. (1974). Interaction of a Cumulus Cloud Ensemble with the Large-Scale Environment, Part I. J. Atmos. Sci., 31, 674-701. doi: 10 .1175/1520-0469(1974)031\%3C0674:IOACCE\%3E2.0.CO;2

Arbuszewski, J. A., Demenocal, P. B., Cléroux, C., Bradtmiller, L., \& Mix, A. (2013). Meridional shifts of the Atlantic Intertropical Convergence Zone since the Last Glacial Maximum. $\quad$ Nature Geoscience, 6(11), 959-962. doi: 10.1038/ngeo1961

Back, L. E., \& Bretherton, C. S. (2009). On the relationship between SST gradients, boundary layer winds, and convergence over the tropical oceans. Journal of Climate, 22(15), 4182-4196.

Baldwin, J. W., Vecchi, G. A., \& Bordoni, S. (2019). The direct and ocean-mediated influence of Asian orography on tropical precipitation and cyclones. Climate Dynamics, 1-20. Retrieved from http://dx.doi.org/10.1007/s00382-019 -04615-5http://link. springer.com/10.1007/s00382-019-04615-5 doi: 10 $.1007 / \mathrm{s} 00382-019-04615-5$

Barlow, M., Nigam, S., \& Berbery, E. H. (1998). Evolution of the North American Monsoon System. Journal of Climate, 11(9), 2238-2257. doi: 10.1175/1520 -0442(1998)011〈2238:EOTNAM $\rangle$ 2.0.CO;2

Battisti, D. S., Ding, Q., \& Roe, G. H. (2014). Coherent pan-Asian climatic and isotopic response to orbital forcing of tropical insolation. Journal of Geophysical Research, 119(21), 11,997-12,020. doi: 10.1002/2014JD021960

Battisti, D. S., Vimont, D. J., \& Kirtman, B. P. (2019). 100 years of progress in understanding the dynamics of coupled atmosphere-ocean variability. Meteorological Monographs. doi: 10.1175/AMSMONOGRAPHS-D-18-0025.1

Becker, E., Schmitz, G., \& Geprägs, R. (1997). The feedback of midlatitude waves onto the Hadley cell in a simple general circulation model. Tellus A, 49, 182199.

Biasutti, M., Voigt, A., Boos, W. R., Braconnot, P., Hargreaves, J. C., Harrison, S. P., .. Xie, S.-P. (2018). Global energetics and local physics as drivers of past, present and future monsoons. Nature Geoscience, 11(6), 392-400. doi: 10.1038/s41561-018-0137-1

Bischoff, T., \& Schneider, T. (2014). Energetic constraints on the position of the Intertropical Convergence Zone. Journal of Climate, 27(13), 4937-4951. doi: 10 .1175/JCLI-D-13-00650.1

Bischoff, T., \& Schneider, T. (2016). The equatorial energy balance, ITCZ position, and double-ITCZ bifurcations. Journal of Climate, 29(8), 2997-3013. doi: 10 $.1175 /$ JCLI-D-15-0328.1

Bond, G., Broecker, W., Johnsen, S., McManus, J., Labeyrie, L., Jouzel, J., \& Bonani, G. (1993). Correlations between climate records from North Atlantic sediments and Greenland ice. Nature, 365, 143-147.

Boos, W. R., \& Korty, R. L. (2016). Regional energy budget control of the Intertropical Convergence Zone and application to mid-Holocene rainfall. Nature 
Geoscience, 9(12), 892-897. doi: 10.1038/ngeo2833

Boos, W. R., \& Kuang, Z. (2010). Dominant control of the South Asian monsoon by orographic insulation versus plateau heating. Nature, 463(7278), 218-222. doi: $10.1038 /$ nature 08707

Bordoni, S., Ciesielski, P. E., Johnson, R. H., McNoldy, B. D., \& Stevens, B. (2004). The low-level circulation of the North American Monsoon as revealed by QuikSCAT. Geophysical Research Letters, 31, L10109. doi 10.1029/2004GL020009

Bordoni, S., \& Schneider, T. (2008). Monsoons as eddy-mediated regime transitions of the tropical overturning circulation. Nature Geoscience, 1(8), 515-519. doi: $10.1038 /$ ngeo248

Bordoni, S., \& Schneider, T. (2010). Regime Transitions of Steady and TimeDependent Hadley Circulations: Comparison of Axisymmetric and EddyPermitting Simulations. Journal of the Atmospheric Sciences, 67(5), 16431654. doi: 10.1175/2009JAS3294.1

Broccoli, A. J., Dahl, K. A., \& Stouffer, R. J. (2006). Response of the ITCZ to Northern Hemisphere cooling. Geophysical Research Letters, 33(1), 1-4. doi: 10.1029/2005GL024546

Burpee, R. W. (1972). The origin and structure of easterly waves in the lower troposphere of North Africa. Journal of the Atmospheric Sciences, 29(1), 77-90.

Burpee, R. W. (1974). Characteristics of North African easterly waves during the summers of 1968 and 1969. Journal of the Atmospheric Sciences, 31(6), 15561570 .

Byerle, L. A., \& Paegle, J. (2002). Description of the Seasonal Cycle of Low-Level Flows Flanking the Andes and their Interannual Variability. Meteorologica, 27, $71-88$.

Campetella, C. M., \& Vera, C. S. (2002). The influence of the Andes mountains on the South American low-level flow. Geophysical Research Letters, 29(17), 7:14. doi: $10.1029 / 2002 \mathrm{~g} 1015451$

Carolin, S. A., Cobb, K. M., Adkins, J. F., Clark, B., Conroy, J. L., Lejau, S., ... Tuen, A. A. (2013). Varied Response of Western Pacific Hydrology to Climate Forcings over the Last Glacial Period. Science, 340(6140), 1564-1566. doi: 10.1126/science. 1233797

Charney, J. G., \& Drazin, P. G. (1961). Propagation of planetary-scale disturbances from the lower into the upper atmosphere. Journal of Geophysical Research, 66(1), 83-109. Retrieved from https://agupubs.onlinelibrary.wiley.com/ doi/abs/10.1029/JZ066i001p00083 doi: 10.1029/JZ066i001p00083

Chen, J., \& Bordoni, S. (2014). Orographic Effects of the Tibetan Plateau on the East Asian Summer Monsoon: An Energetic Perspective. Journal of Climate, 27(8), 3052-3072. doi: 10.1175/JCLI-D-13-00479.1

Cheng, H., Sinha, A., Wang, X., Cruz, F. W., \& Edwards, R. L. (2012). The Global Paleomonsoon as seen through speleothem records from Asia and the Americas. Climate Dynamics, 39, 1045-1062. doi: 10.1007/s00382-012-1363-7

Cheng, Y.-M., Thorncroft, C. D., \& Kiladis, G. N. (2019). Two contrasting African easterly wave behaviors. Journal of the Atmospheric Sciences, 76 (6), 17531768 .

Chiang, J., Wu, C., Kong, W., \& Battisti, D. (2020). Origins of East Asian Summer Monsoon Seasonality. Revised, Journal of Climate.

Chiang, J. C., \& Friedman, A. R. (2012). Extratropical cooling, interhemispheric thermal gradients, and tropical climate change. Annual Review of Earth and Planetary Sciences, 40.

Chiang, J. C. H., \& Bitz, C. M. (2005). Influence of high latitude ice cover on the marine Intertropical Convergence Zone. Climate Dynamics, 25(5), 477-496. doi: $10.1007 / \mathrm{s} 00382-005-0040-5$

Chiang, J. C. H., Fung, I. Y., Wu, C.-H., Cai, Y., Edman, Jacob, P., Liu, Y., ... 
(2015). Role of seasonal transitions and westerly jets in East Asian paleoclimate. Quaternary Science Reviews, 108, 111-129. doi: 10.1016/j.quascirev.2014.11.009

Chiang, J. C. H., Swenson, L. M., \& Kong, W. (2017). Role of seasonal transitions and the westerlies in the interannual variability of the East Asian summer monsoon precipitation. Geophysical Research Letters, 44(8), 3788-3795. doi: 10.1002/2017GL072739

Chiang, J. C. H., Zebiak, S. E., \& Cane, M. A. (2001). Relative roles of elevated heating and surface temperature gradients in driving anomalous surface winds over tropical oceans. Journal of the Atmospheric Sciences, 58(11), 1371-1394.

Chou, C., \& Neelin, J. D. (2001). Mechanisms limiting the southward extend of the South American summer monsoon. Geophysical Research Letters, 28(12), 2433-2436. doi: 10.1029/2000GL012138

Chou, C., \& Neelin, J. D. (2003). Mechanisms limiting the northward extent of the northern summer monsoons over North America, Asia, and Africa. Journal of Climate, 16(3), 406-425. doi: 10.1175/1520-0442(2003)016<0406:MLTNEO $>2.0$ $\mathrm{CO} ; 2$

Christensen, J., Krishna Kumar, K., Aldrian, E., An, S.-I., Cavalcanti, I., de Castro, M., ... Zhou, T. (2013). Climate phenomena and their relevance for future regional climate change [Book Section]. In T. Stocker et al. (Eds.), Climate Change 2013: The Physical Science Basis. Contribution of Working Group I to the Fifth Assessment Report of the Intergovernmental Panel on Climate Change (p. 12171308). Cambridge, United Kingdom and New York, NY, USA: Cambridge University Press. Retrieved from www.climatechange2013.org doi: $10.1017 /$ CBO9781107415324.028

Cook, K. H. (2000). The South Indian Convergence Zone and Interannual Rainfall Variability over Southern Africa. Journal of Climate, 13(21), 3789-3804. doi: 10.1175/1520-0442(2000)013〈3789:TSICZA $\rangle 2.0 . C O ; 2$

D’Agostino, R., Bader, J., Bordoni, S., Ferreira, D., \& Jungclaus, J. (2019). Northern Hemisphere Monsoon Response to Mid-Holocene Orbital Forcing and Greenhouse Gas-Induced Global Warming. Geophysical Research Letters, 1-11. doi: 10.1029/2018GL081589

Deplazes, G., Lckge, A., Peterson, L. C., Timmermann, A., Hamann, Y., Hughen, K. A., ... Haug, G. H. (2013). Links between tropical rainfall and North Atlantic climate during the last glacial period. Nature Geosci, 6, 213-217. doi: $10.1038 /$ ngeo1712

Diaz, M., \& Boos, W. R. (2019a). Barotropic growth of monsoon depressions. Quarterly Journal of the Royal Meteorological Society, 145(719), 824-844.

Diaz, M., \& Boos, W. R. (2019b). Monsoon depression amplification by moist barotropic instability in a vertically sheared environment. Quarterly Journal of the Royal Meteorological Society, 145(723), 2666-2684. doi: 10.1002/qj.3585

Ding, Y., \& Chan, J. C. L. (2005). The East Asian summer monsoon: An overview. Meteorology and Atmospheric Physics, 89(1), 117-142. doi: 10.1007/s00703-005-0125-Z

Donohoe, A., Marshall, J., Ferreira, D., \& Mcgee, D. (2013). The relationship between ITCZ location and cross-equatorial atmospheric heat transport: From the seasonal cycle to the last glacial maximum. Journal of Climate, 26(11), 3597-3618. doi: 10.1175/JCLI-D-12-00467.1

Egger, J., Weickmann, K., \& Hoinka, K.-P. (2007). Angular momentum in the global atmospheric circulation. Reviews of Geophysics, 45(4). Retrieved from https://agupubs.onlinelibrary.wiley.com/doi/abs/10.1029/ 2006RG000213 doi: 10.1029/2006RG000213

Ellis, A. W., Saffell, E. M., \& Hawkins, T. W. (2004). A method for defining monsoon onset and demise in the Southwestern USA. International Journal of Climatology, 24(2), 247-265. doi: 10.1002/joc.996 
Eltahir, E. A., \& Gong, C. (1996). Dynamics of Wet and Dry Years in West Africa. Journal of Climate, 9, 1030-1042. doi: 10.1175/1520-0442(1996)009\%3C1030: DOWADY\%3E2.0.CO;2

Emanuel, K. A. (1983a). The Lagrangian parcel dynamics of moist symmetric instability. Journal of the Atmospheric Sciences, 40, 2368-2376.

Emanuel, K. A. (1983b). On assessing local conditional symmetric instability from atmospheric soundings. Monthly weather review, 111, 2016-2033.

Emanuel, K. A. (1988). Observational evidence of slantwise convective adjustment. Monthly weather review, 116(9), 1805-1816.

Emanuel, K. A. $\quad$ (1995). On Thermally Direct Circulations in Moist Atmospheres. Journal of the Atmospheric Sciences, 52(9), 1529-1534. doi: 10.1175/1520-0469(1995)052〈1529:OTDCIM $\rangle 2.0 . C O ; 2$

Emanuel, K. A., Neelin, J. D., \& Bretherton, C. S. (1994). On large-scale circulations in convecting atmospheres. Quarterly Journal of the Royal Meteorological Society, 120(519), 1111-1143. doi: 10.1002/qj.49712051902

Eroglu, D., McRobie, F. H., Ozken, I., Stemler, T., Wyrwoll, K. H., Breitenbach, S. F., ... Kurths, J. (2016). See-saw relationship of the Holocene East Asian-Australian summer monsoon. $\quad$ Nature Communications, 7, 1-7. doi: 10.1038/ncomms12929

Faulk, S., Mitchell, J., \& Bordoni, S. (2017). Effects of Rotation Rate and Seasonal Forcing on the ITCZ Extent in Planetary Atmospheres. Journal of the Atmospheric Sciences, 74(3), 665-678. doi: 10.1175/JAS-D-16-0014.1

Frierson, D. M., Hwang, Y. T., Fučkar, N. S., Seager, R., Kang, S. M., Donohoe, A., ... Battisti, D. S. (2013). Contribution of ocean overturning circulation to tropical rainfall peak in the Northern Hemisphere. Nature Geoscience, 6(11), 940-944. doi: $10.1038 /$ ngeo1987

Frierson, D. M. W. (2007). The Dynamics of Idealized Convection Schemes and Their Effect on the Zonally Averaged Tropical Circulation. Journal of the Atmospheric Sciences, 64(6), 1959-1976. doi: 10.1175/JAS3935.1

Frierson, D. M. W., \& Hwang, Y. T. (2012). Extratropical influence on ITCZ shifts in slab ocean simulations of global warming. Journal of Climate, 25(2), 720733. doi: $10.1175 /$ JCLI-D-11-00116.1

Fučkar, N. S., Xie, S.-P., Farneti, R., Maroon, E. A., \& Frierson, D. M. (2013). Influence of the extratropical ocean circulation on the intertropical convergence zone in an idealized coupled general circulation model. Journal of Climate, 26 (13), 4612-4629. doi: 10.1175/JCLI-D-12-00294.1

Gadgil, S. (2018). The monsoon system: Land-sea breeze or the ITCZ? Journal of Earth System Science, 127(1), 1-29. doi: 10.1007/s12040-017-0916-x

Geen, R., Lambert, F. H., \& Vallis, G. K. (2018). Regime Change Behavior During Asian Monsoon Onset. Journal of Climate, 31,3327-3348. Retrieved from http://journals . ametsoc.org/doi/10.1175/JCLI-D-17-0118.1 doi: 10.1175/JCLI-D-17-0118.1

Geen, R., Lambert, F. H., \& Vallis, G. K. (2019). Processes and Timescales in Onset and Withdrawal of Aquaplanet Monsoons'. Journal of the Atmospheric Sciences.

Godbole, R. V. (1977). The composite structure of the monsoon depression. Tellus, 29(1), 25-40.

Goswami, B. N., \& Ajaya Mohan, R. S. (2001). Intraseasonal Oscillations and Interannual Variability of the Indian Summer Monsoon. Journal of Climate, 14, 1180-1198. doi: 10.1175/1520-0442(2001)014〈1180:IOAIVO $\rangle 2.0 . C O ; 2$

Gottschalck, J. (2014). What is the MJO, and why do we care? https://www .climate.gov/news-features/blogs/enso/what-mjo-and-why-do-we-care. NOAA climate.gov. (Accessed: 2019-12-24)

Green, B., \& Marshall, J. (2017). Coupling of Trade Winds with Ocean Circulation Damps ITCZ Shifts. Journal of Climate, 30(12), 4395-4411. Retrieved from 
https://doi.org/10.1175/JCLI-D-16-0818.1 doi: 10.1175/JCLI-D-16-0818 .1

Gruber, A., Su, X., Kanamitsu, M., \& Schemm, J. $\quad$ (2000). The Comparison of Two Merged Rain Gauge-Satellite Precipitation Datasets. Bulletin of the American Meteorological Society, 81(11), 2631-2644. doi: 10.1175/1520-0477(2000)081<2631:TCOTMR $\rangle 2.3 . \mathrm{CO} ; 2$

Hagos, S. M., \& Cook, K. H. (2007). Dynamics of the West African monsoon jump. Journal of Climate, 20(21), 5264-5284. doi: 10.1175/2007JCLI1533.1

Halley, E. (1686). An Historical Account of the Trade Winds, and Monsoons, Observable in the Seas between and Near the Tropicks, with an Attempt to Assign the Phisical Cause of the Said Winds, By E. Halley. Philosophical Transactions of the Royal Society of London, 16(179-191), 153-168. doi: $10.1098 /$ rstl.1686.0026

Hartmann, D. L., \& Michelsen, M. L. (1989). Intraseasonal periodicities in Indian rainfall. Journal of the Atmospheric Sciences, 46(18), 2838-2862.

Held, I. M. (2005). The gap between simulation and understanding in climate modeling. Bulletin of the American Meteorological Society, 86(11), 16091614. Retrieved from https://doi.org/10.1175/BAMS-86-11-1609 doi: 10.1175/BAMS-86-11-1609

Held, I. M., \& Coauthors. (2000). The General Circulation of the Atmosphere. Woods Hole Oceanographic Institution.

Hendon, H. H., \& Liebmann, B. (1990). A Composite Study of Onset of the Australian Summer Monsoon. Journal of Atmospheric Sciences, 47 (18), 22272240. doi: 10.1175/1520-0469(1990)047 $\langle 2227$ :ACSOOO $\rangle$ 2.0.CO;2

Hide, R. (1969). Dynamics of the Atmospheres of the Major Planets with an Appendix on the Viscous Boundary Layer at the Rigid Bounding Surface of an Electrically-Conducting Rotation Fluid in the Presence of a Magnetic Field. J. Atmos. Sci., 26, 841-853. doi: 10.1175/1520-0469(1969)026\%3C0841: DOTAOT\%3E2.0.CO;2

Hilgenbrink, C. C., \& Hartmann, D. L. (2018). The response of Hadley circulation extent to an idealized representation of poleward ocean heat transport in an aquaplanet GCM. Journal of Climate, 31, 9753-9770.

Hill, S. A. (2019). Theories for Past and Future Monsoon Rainfall Changes. Current Climate Change Reports, 5, 160-171.

Hill, S. A., Bordoni, S., \& Mitchell, J. L. (2019). Hadley cell emergence and extent in axisymmetric, nearly inviscid, planetary atmospheres. J. Atmos. Sci..

Hill, S. A., Ming, Y., \& Held, I. M. (2015). Mechanisms of forced tropical meridional energy flux change. Journal of Climate, 28, 1725-1742. doi: 10.1175/JCLI-D $-14-00165.1$

Hill, S. A., Ming, Y., Held, I. M., \& Zhao, M. (2017). A moist static energy budgetbased analysis of the Sahel rainfall response to uniform oceanic warming. Journal of Climate, 30(15), 5637-5660. doi: 10.1175/JCLI-D-16-0785.1

Hill, S. A., Ming, Y., \& Zhao, M. (2018). Robust Responses of the Hydrological Cycle to Global Warming. Journal of Climate, 1931, 9793-9814. doi: 10.1175/ JCLI-D-18-0238.1

Holton, J. R., Wallace, J. M., \& Young, J. (1971). On boundary layer dynamics and the ITCZ. Journal of the Atmospheric Sciences, 28(2), 275-280.

Houze Jr, R. A. (2018). 100 years of research on mesoscale convective systems. Meteorological Monographs, 59, 17-1.

Huffman, G. J., Adler, R. F., Morrissey, M. M., Bolvin, D. T., Curtis, S., Joyce, R., ... Susskind, J. (2001). Global Precipitation at One-Degree Daily Resolution from Multisatellite Observations. Journal of Hydrometeorology, 2, 36-50.

Hui, K., \& Bordoni, S. (in prep.). Influence of Continental Geometry on the Onset and Spatial Distribution of Monsoonal Precipitation.

Hunt, K. M., Turner, A. G., Inness, P. M., Parker, D. E., \& Levine, R. C. (2016). 
On the structure and dynamics of Indian monsoon depressions. Weather Review, 144 (9), 3391-3416.

Hurley, J. V., \& Boos, W. R. (2013). Interannual variability of monsoon precipitation and local subcloud equivalent potential temperature. Journal of Climate, 26 (23), 9507-9527. doi: 10.1175/JCLI-D-12-00229.1

Hurley, J. V., \& Boos, W. R. (2015). A global climatology of monsoon low-pressure systems. Quarterly Journal of the Royal Meteorological Society, 141(689), 1049-1064. doi: 10.1002/qj.2447

Jeevanjee, N., Hassanzadeh, P., Hill, S., \& Sheshadri, A. (2017). A perspective on climate model hierarchies. Journal of Advances in Modeling Earth Systems, 9(4), 1760-1771. doi: 10.1002/2017MS001038

Jiang, X., Adames, . F., Zhao, M., Waliser, D., \& Maloney, E. (2018). A unified moisture mode framework for seasonality of the Madden-Julian oscillation. Journal of Climate, 31(11), 4215-4224. Retrieved from https://doi.org/ 10.1175/JCLI-D-17-0671.1 doi: 10.1175/JCLI-D-17-0671.1

Jourdain, N. C., Gupta, A. S., Taschetto, A. S., Ummenhofer, C. C., Moise, A. F., \& Ashok, K. (2013). The Indo-Australian monsoon and its relationship to ENSO and IOD in reanalysis data and the CMIP3/CMIP5 simulations. Climate Dynamics, 41(11), 3073-3102. Retrieved from https://doi.org/10.1007/ s00382-013-1676-1 doi: 10.1007/s00382-013-1676-1

Kang, S. M., Frierson, D. M. W., \& Held, I. M. (2009). The Tropical Response to Extratropical Thermal Forcing in an Idealized GCM: The Importance of Radiative Feedbacks and Convective Parameterization. Journal of the Atmospheric Sciences, 66 (9), 2812-2827. doi: 10.1175/2009jas2924.1

Kang, S. M., \& Held, I. M. (2012). Tropical precipitation, SSTs and the surface energy budget: A zonally symmetric perspective. Climate Dynamics, 38(9-10), 1917-1924. doi: 10.1007/s00382-011-1048-7

Kang, S. M., Held, I. M., Frierson, D. M., \& Zhao, M. (2008). The response of the ITCZ to extratropical thermal forcing: Idealized slab-ocean experiments with a GCM. Journal of Climate, 21(14), 3521-3532. doi: 10.1175/2007JCLI2146.1

Kerns, B., \& Chen, S. S. (2020). A 20-year climatology of Madden-Julian Oscillation convection: Large-scale precipitation tracking from TRMM-GPM rainfall. In press, J. Geophys. Res. Atmos..

Kiladis, G. N., Thorncroft, C. D., \& Hall, N. M. J. (2006). Three-Dimensional Structure and Dynamics of African Easterly Waves. Part I: Observations. Journal of the Atmospheric Sciences, 63(9), 2212-2230. doi: 10.1175/JAS3741.1

Kiladis, G. N., Wheeler, M. C., Haertel, P. T., Straub, K. H., \& Roundy, P. E. (2009). Convectively coupled equatorial waves. Reviews of Geophysics, 47 (RG2003).

Kobayashi, S., Ota, Y., Harada, Y., Ebita, A., Moriya, M., Onoda, H., ... Takahashi, K. (2015). The JRA-55 Reanalysis: General Specifications and Basic Characteristics. J. Meteorol. Soc. Jpn., 93(1), 5-48. doi: 10.2151/ jmsj.2015-001

Kodama, Y. (1992). Large-Scale Common Features of Subtropical Precipitation Zones (the Baiu Frontal Zone, the SPCZ, and the SACZ). Part I: Characteristics of Subtropical Frontal Zones. Journal of the Meteorological Society of Japan, 70 (4), 813-836. doi: 10.2151/jmsj1965.70.4_813

Kong, W., \& Chiang, J. C. H. (2020). Interaction of the Westerlies with the Tibetan Plateau in Determining the Mei-Yu Termination. Journal of Climate, 33(1), 339-363. doi: 10.1175/JCLI-D-19-0319.1

Kong, W., Swenson, L. M., \& Chiang, J. C. H. (2017). Seasonal transitions and the westerly jet in the Holocene East Asian summer monsoon. Journal of Climate, 30(9), 3343-3365. doi: 10.1175/JCLI-D-16-0087.1

Kothawale, D., \& Kumar, K. R. (2002). Tropospheric temperature variation over India and links with the Indian summer monsoon: 1971-2000. Mausam, 53, 289- 
308.

Lea, D. W., Pak, D. K., Peterson, L. C., \& Hughen, K. A. $\quad$ (2003). Temperatures over the Last Glacial Termination Synchroneity of Tropical and High-Latitude Atlantic Temperatures over the Last Glacial Termination. Science, 301, 13611364. doi: $10.1126 /$ science. 1088470

Lebel, T. (2003). Seasonal cycle and interannual variability of the Sahelian rainfall at hydrological scales. Journal of Geophysical Research, 108(D8), 8389. doi: 10 .1029/2001JD001580,

Lee, J.-Y., Wang, B., Wheeler, M. C., Fu, X., Waliser, D. E., \& Kang, I.-S. (2013). Real-time multivariate indices for the boreal summer intraseasonal oscillation over the Asian summer monsoon region. Climate Dynamics, 40(1), 493509. Retrieved from https://doi.org/10.1007/s00382-012-1544-4 doi: 10.1007/s00382-012-1544-4

Lenters, J. D., \& Cook, K. H. (1997). On the Origin of the Bolivian High and Related Circulation Features of the South American Climate. Journal of the Atmospheric Sciences, 54, 656-678. doi: 10.1175/1520-0469(1997)054\%3C0656: OTOOTB\%3E2.0.CO;2

Levine, X. J., \& Schneider, T. (2011). Response of the Hadley Circulation to Climate Change in an Aquaplanet GCM Coupled to a Simple Representation of Ocean Heat Transport. Journal of the Atmospheric Sciences, 68(4), 769-783. Retrieved from https://doi.org/10.1175/2010JAS3553.1 doi: 10.1175/2010JAS3553.1

Levy, G., \& Battisti, D. S. (1995). The symmetric stability and the low level equatorial flow. Global Atmosphere-Ocean System, 3(4), 341-354.

Liebmann, B., \& Hendon, H. H. (1990). Synoptic-scale disturbances near the equator. Journal of the Atmospheric Sciences, 47(12), 1463-1479.

Lindzen, R. S., \& Hou, A. Y. (1988). Hadley Circulations for Zonally Averaged Heating Centred off the Equator. J. Atmos. Sci., 45(17), 2416-2427.

Lindzen, R. S., \& Nigam, S. (1987). On the role of sea surface temperature gradients in forcing low-level winds and convergence in the tropics. Journal of the Atmospheric Sciences, 44(17), 2418-2436.

Linho, L. H., Huang, X., \& Lau, N. C. (2008). Winter-to-spring transition in east Asia: A planetary-scale perspective of the south China spring rain onset. Journal of Climate, 21 (13), 3081-3096. doi: 10.1175/2007JCLI1611.1

Liu, X., \& Battisti, D. S. (2015). The influence of orbital forcing of tropical insolation on the climate and isotopic composition of precipitation in South America. Journal of Climate, 28(12), 4841-4862.

Liu, X., Battisti, D. S., \& Donohoe, A. (2017). Tropical precipitation and crossequatorial ocean heat transport during the mid-Holocene. Journal of Climate, 30 (10), 3529-3547. doi: 10.1175/JCLI-D-16-0502.1

Madden, R. A., \& Julian, P. R. (1971). Detection of a 40-50 day oscillation in the zonal wind in the tropical Pacific. Journal of the Atmospheric Sciences, 28(5), 702-708.

Madden, R. A., \& Julian, P. R. (1972). Description of global-scale circulation cells in the tropics with a 40-50 day period. Journal of the Atmospheric Sciences, 29(6), 1109-1123.

Maher, P., Gerber, E. P., Medeiros, B., Merlis, T. M., Sherwood, S., Sheshadri, A., ... ZuritaGotor, P. (2019). Model Hierarchies for Understanding Atmospheric Circulation. Reviews of Geophysics, 2018RG000607. Retrieved from https://onlinelibrary.wiley.com/doi/abs/10.1029/2018RG000607 doi: 10.1029/2018RG000607

Mao, J., \& Wu, G. (2007). Interannual variability in the onset of the summer monsoon over the Eastern Bay of Bengal. Theoretical and Applied Climatology, 89(3-4), 155-170. doi: 10.1007/s00704-006-0265-1

Marengo, J. A., Liebmann, B., Grimm, A. M., Misra, V., Silva Dias, P. L., Cav- 
alcanti, I. F., ... Alves, L. M. (2012). Recent developments on the South American monsoon system. International Journal of Climatology, 32(1), 1-21. doi: $10.1002 /$ joc. 2254

Maroon, E. A., Frierson, D. M., \& Battisti, D. S. (2015). The tropical precipitation response to Andes topography and ocean heat fluxes in an aquaplanet model. Journal of Climate, 28(1), 381-398. doi: 10.1175/JCLI-D-14-00188.1

Marshall, J., Donohoe, A., Ferreira, D., \& McGee, D. (2014). The ocean's role in setting the mean position of the Inter-Tropical Convergence Zone. Climate Dynamics, 42(7-8), 1967-1979. doi: 10.1007/s00382-013-1767-z

Martin, G. M., Chevuturi, A., Comer, R. E., Dunstone, N. J., Scaife, A. A., \& Zhang, D. (2019). Predictability of South China Sea Summer Monsoon Onset. $\quad$ Advances in Atmospheric Sciences, 36(3), 253-260. doi: $10.1007 / \mathrm{s} 00376-018-8100-\mathrm{z}$

Matsuno, T. (1966). Quasi-Geostrophic Motions in the Equatorial Area. J. Meteor. Soc. Japan, 44(1), 25-43. doi: 10.2151/jmsj1965.44.1_25

McGee, D., Donohoe, A., Marshall, J., \& Ferreira, D. (2014). C Changes in ITCZ location and cross-equatorial heat transport at the Last Glacial Maximum, Heinrich Stadial 1, and the mid-Holocene. Earth and Planetary Science Letters, 390, 69-79. doi: 10.1016/j.epsl.2013.12.043

Merlis, T. M., Schneider, T., Bordoni, S., \& Eisenman, I. （2013). Hadley circulation response to orbital precession. Part I: Aquaplanets. Journal of Climate, 26, 740-753. doi: 10.1175/JCLI-D-11-00716.1

Molnar, P., Boos, W. R., \& Battisti, D. S. (2010). Orographic controls on climate and paleoclimate of Asia: thermal and mechanical roles for the Tibetan Plateau. Annual Review of Earth and Planetary Sciences, 38(1), 77-102. doi: 10.1146/annurev-earth-040809-152456

Mooley, D. A. (1973). Some aspects of Indian monsoon depression and associated rainfall. Monthly Weather Review, 101, 271-280.

Nicholson, S. E. (2009a). On the factors modulating the intensity of the tropical rainbelt over West Africa. International Journal of Climatology, 29(5), 673689.

Nicholson, S. E. (2009b). A revised picture of the structure of the "monsoon" and land ITCZ over West Africa. Climate Dynamics, 32(7-8), 1155-1171. doi: 10 .1007/s00382-008-0514-3

Nicholson, S. E. (2017). Climate and climatic variability of rainfall over eastern Africa. Reviews of Geophysics, 590-635. doi: 10.1002/2016RG000544

Nie, J., Boos, W. R., \& Kuang, Z. (2010). Observational evaluation of a convective quasi-equilibrium view of monsoons. Journal of Climate, 23(16), 4416-4428. doi: 10.1175/2010JCLI3505.1

Parthasarathy, B., Munot, A. A., \& Kothawale, D. R. (1994). All-India monthly and seasonal rainfall series: 1871-1993. Theoretical and Applied Climatology, 49(4), 217-224. doi: 10.1007/BF00867461

Pausata, F. S., Battisti, D. S., Nisancioglu, K. H., \& Bitz, C. M. (2011). Chinese stalagmite $\delta^{18} \mathrm{O}$ controlled by changes in the Indian monsoon during a simulated Heinrich event. Nature Geoscience, 4(7), 474.

Plumb, R. A., \& Hou, A. Y. (1992). The response of a zonally symmetric atmosphere to subtropical thermal forcing - Threshold behavior. Journal of the Atmospheric Sciences, 49(19), 1790-1799. doi: 10.1175/1520-0469(1992) 049〈1790:TROAZS $>2.0 . \mathrm{CO} ; 2$

Privé, N. C., \& Plumb, R. A. (2007a). Monsoon Dynamics with Interactive Forcing. Part I: Axisymmetric Studies. Journal of the Atmospheric Sciences, 64 (5), 1417-1430. doi: 10.1175/JAS3916.1

Privé, N. C., \& Plumb, R. A. (2007b). Monsoon Dynamics with Interactive Forcing. Part II: Impact of Eddies and Asymmetric Geometries. Journal of the Atmospheric Sciences, 64(5), 1431-1442. doi: 10.1175/JAS3917.1 
Rao, V. B., Cavalcanti, I. F. A., \& Hada, K. (1996). Annual variation of rainfall over Brazil and water vapor characteristics over South America. Journal of Geophysical Research: Atmospheres, 101(D21), 26539-26551. doi: 10.1029/96JD01936

Reed, R. J., Norquist, D. C., \& Recker, E. E. (1977). The structure and properties of African wave disturbances as observed during Phase III of GATE. Monthly Weather Review, 105(3), 317-333.

Rodwell, M. J., \& Hoskins, B. J. (2001). Subtropical anticyclones and summer monsoons. Journal of Climate, 14 (15), 3192-3211. doi: 10.1175/1520-0442(2001) 014<3192:SAASM $\rangle 2.0 . \mathrm{CO} ; 2$

Roehrig, R., Bouniol, D., Guichard, F., Hourdin, F., \& Redelsperger, J.-L. (2013). The Present and Future of the West African Monsoon: A Process-Oriented Assessment of CMIP5 Simulations along the AMMA Transect. Journal of Climate, 26(17),6471-6505. Retrieved from https://doi.org/10.1175/ JCLI-D-12-00505. 1 doi: 10.1175/JCLI-D-12-00505.1

Roundy, P. E., \& Frank, W. M. (2004). A climatology of waves in the equatorial region. Journal of the Atmospheric Sciences, 61 (17), 2105-2132.

Sampe, T., \& Xie, S.-P. (2010). Large-scale dynamics of the Meiyu-Baiu rainband: Environmental forcing by the westerly jet. Journal of Climate, 23(1), 113-134. doi: 10.1175/2009JCLI3128.1

Schneider, T. (2017). Feedback of Atmosphere-Ocean Coupling on Shifts of the Intertropical Convergence Zone. Geophysical Research Letters, $44(22), 11,644$ 11,653. Retrieved from https://agupubs.onlinelibrary.wiley.com/doi/ abs/10.1002/2017GL075817 doi: 10.1002/2017GL075817

Schneider, T., Bischoff, T., \& Haug, G. H. (2014). Migrations and dynamics of the Intertropical Convergence Zone. Nature, 513(7516), 45-53. doi: 10.1038/ nature13636

Schneider, T., \& Bordoni, S. (2008). $\quad$ Eddy-Mediated Regime Transitions in the Seasonal Cycle of a Hadley Circulation and Implications for Monsoon Dynamics. Journal of the Atmospheric Sciences, 65(1), 915-934. doi: 10.1175/2007JAS2415.1

Schumacher, C., \& Houze Jr, R. A. (2003). Stratiform rain in the tropics as seen by the TRMM precipitation radar. Journal of Climate, 16(11), 1739-1756.

Schwendike, J., Govekar, P., Reeder, M. J., Wardle, R., Berry, G. J., \& Jakob, C. (2014). Local partitioning of the overturning circulation in the tropics and the connection to the Hadley and Walker circulations. Journal of Geophysical Research, 119 (3), 1322-1339. doi: 10.1002/2013JD020742

Segele, Z. T., \& Lamb, P. J. (2005). Characterization and variability of Kiremt rainy season over Ethiopia. Meteorology and Atmospheric Physics, 89(1-4), 153-180. doi: 10.1007/s00703-005-0127-x

Seo, J., Kang, S. M., \& Merlis, T. M. (2017). A model intercomparison of the tropical precipitation response to a $\mathrm{CO}_{2}$ doubling in aquaplanet simulations. Geophysical Research Letters, 44(2), 993-1000. Retrieved from https://agupubs .onlinelibrary.wiley.com/doi/abs/10.1002/2016GL072347 doi: 10.1002/ 2016GL072347

Seth, A., Giannini, A., Rojas, M., Rauscher, S. A., Bordoni, S., Singh, D., \& Camargo, S. J. (2019, Jun 01). Monsoon responses to climate changesconnecting past, present and future. Current Climate Change Reports, 5(2), 63-79. Retrieved from https://doi.org/10.1007/s40641-019-00125-y doi: 10.1007/s40641-019-00125-y

Shaw, T. A. (2014). On the Role of Planetary-Scale Waves in the Abrupt Seasonal Transition of the Northern Hemisphere General Circulation. Journal of the Atmospheric Sciences, 71(5), 1724-1746. doi: 10.1175/JAS-D-13-0137.1

Shaw, T. A., \& Voigt, A. (2015). Tug of war on summertime circulation between radiative forcing and sea surface warming. Nature Geoscience, 8(7), 560-566. 
doi: $10.1038 /$ ngeo2449

Shekhar, R., \& Boos, W. R. (2016). Improving energy-based estimates of monsoon location in the presence of proximal deserts. Journal of Climate, 29(13), 47414761. doi: $10.1175 /$ JCLI-D-15-0747.1

Sikka, D. (1978). Some aspects of the life history, structure and movement of monsoon depressions. In Monsoon dynamics (pp. 1501-1529). Springer.

Sikka, D. R., \& Gadgil, S. (1980). On the Maximum Cloud Zone and the ITCZ over Indian, Longitudes during the Southwest Monsoon. Monthly Weather Review, 108(11), 1840-1853. Retrieved from https://doi.org/ 10.1175/1520-0493(1980) 108<1840: OTMCZA>2.0.CO;2 doi: 10.1175/ 1520-0493(1980)108<1840:OTMCZA $>2.0 . C O ; 2$

Simpson, G. (1921). The South-West monsoon. Quarterly Journal of the Royal Meteorological Society, 47(199), 151-171.

Singh, M. S. (2019). Limits on the extent of the solsticial Hadley Cell: The role of planetary rotation. Journal of Atmospheric Sciences.

Smyth, J. E., Hill, S. A., \& Ming, Y. (2018). Simulated Responses of the West African Monsoon and Zonal-Mean Tropical Precipitation to Early Holocene Orbital Forcing. Geophysical Research Letters(Figure 1), 49-57. doi: 10.1029/2018GL080494

Sobel, A., \& Maloney, E. (2013). Moisture Modes and the Eastward Propagation of the MJO. Journal of the Atmospheric Sciences, 70(1), 187-192. Retrieved from https://doi.org/10.1175/JAS-D-12-0189.1 doi: 10.1175/JAS-D-12 $-0189.1$

Sperber, K. R., Annamalai, H., Kang, I.-S., Kitoh, A., Moise, A., Turner, A., .. Zhou, T. (2013). The Asian summer monsoon: An intercomparison of CMIP5 vs. CMIP3 simulations of the late 20th century. Climate Dynamics, 41(9), 2711-2744. Retrieved from https://doi.org/10.1007/s00382-012-1607-6 doi: $10.1007 / \mathrm{s} 00382-012-1607-6$

Stevens, D. E. (1983). On symmetric stability and instability of zonal mean flows near the equator. Journal of the Atmospheric Sciences, 40(4), 882-893.

Sultan, B., \& Janicot, S. (2003). The West African monsoon dynamics. Part II: The preonset and onset of the summer monsoon. Journal of climate, 16(21), 34073427. doi: 10.1175/1520-0442(2003)016<3407:TWAMDP $\rangle 2.0 . C O ; 2$

Takahashi, K. (2005). The annual cycle of heat content in the Peru current region. Journal of Climate, 18(23), 4937-4954. doi: 10.1175/JCLI3572.1

Takahashi, K., \& Battisti, D. S. (2007). Processes Controlling the Mean Tropical Pacific Precipitation Pattern. Part I: The Andes and the Eastern Pacific ITCZ. Journal of Climate, 20(14), 3434-3451. doi: 10.1175/jcli4198.1

Tomas, R. A., \& Webster, P. J. (1997). The role of inertial instability in determining the location and strength of near-equatorial convection. Quarterly Journal of the Royal Meteorological Society, 123(542), 1445-1482.

Trenberth, K. E., Stepaniak, D. P., \& Caron, J. M. (2000). The global monsoon as seen through the divergent atmospheric circulation. Journal of Climate, 13(22), 3969-3993. doi: 10.1175/1520-0442(2000)013<3969: TGMAST $>2.0 . \mathrm{CO} ; 2$

Uppala, S. M., Kållberg, P., Simmons, A., Andrae, U., Bechtold, V. D. C., Fiorino, M., ... others (2005). The ERA-40 re-analysis. Q. J. R. Meteorol. Soc., 131, 2961-3012.

Walker, C. C., \& Schneider, T. (2006). Eddy Influences on Hadley Circulations: Simulations with an Idealized GCM. Journal of the Atmospheric Sciences, 63(12), 3333-3350. Retrieved from http://journals.ametsoc.org/doi/abs/ 10.1175/JAS3821. 1 doi: 10.1175/JAS3821.1

Walker, J. M., \& Bordoni, S. (2016). Onset and withdrawal of the large-scale South Asian monsoon: A dynamical definition using change point detection. Geophysical Research Letters, 43(22), 11,815-11,822. doi: 10.1002/2016GL071026 
Walker, J. M., Bordoni, S., \& Schneider, T. (2015). Interannual variability in the large-scale dynamics of the South Asian summer monsoon. Journal of Climate, 28(9), 3731-3750. doi: 10.1175/JCLI-D-14-00612.1

Wallace, J., Battisti, D., Thompson, D., \& Hartmann, D. (2020). The Atmospheric General Circulation. Under review, Cambridge University Press.

Wang, B., \& Ding, Q. (2006). Changes in global monsoon precipitation over the past 56 years. Geophysical Research Letters, 33(6), L06711. doi: 10.1029/ 2005GL025347

Wang, B., Ding, Q., \& Joseph, P. V. (2009). Objective definition of the Indian summer monsoon onset. Journal of Climate, 22(12), 3303-3316. doi: 10.1175/ 2008JCLI2675.1

Wang, B., \& LinHo. (2002). Rainy Season of the Asian-Pacific Summer Monsoon. Journal of Climate, 15, 386-398. doi: 10.1175/1520-0442(2002)015\%3C0386: RSOTAP\%3E2.0.CO;2

Wang, B., LinHo, Zhang, Y., \& Lu, M. M. (2004). Definition of South China Sea monsoon onset and commencement of the East Asian summer monsoon. Journal of Climate, 17(4), 699-710. doi: 10.1175/2932.1

Wang, B., Liu, J., Kim, H. J., Webster, P. J., \& Yim, S. Y. (2012). Recent change of the global monsoon precipitation (1979-2008). Climate Dynamics, 39(5), 11231135. doi: 10.1007/s00382-011-1266-z

Wang, B., Wu, R., \& Lau, K.-M. (2001). Interannual Variability of the Asian Summer Monsoon: Contrasts between the Indian and the Western North Pacific-East Asian Monsoons. Journal of Climate, 14, 4073-4090. doi: 10.1175/1520-0442(2001)014〈4073:IVOTAS $\rangle 2.0 . C O ; 2$

Wang, B., \& Xie, X. (1997). A model for the boreal summer intraseasonal oscillation. Journal of the Atmospheric Sciences, 54 (1), 72-86. doi: 10.1175/1520 -0469(1997)054〈0072:AMFTBS $\rangle 2.0 . \mathrm{CO} ; 2$

Wang, P. X., Wang, B., Cheng, H., Fasullo, J., Guo, Z. T., Kiefer, T., \& Liu, Z. Y. (2014). The global monsoon across timescales: Coherent variability of regional monsoons. Climate of the Past, 10(6), 2007-2052. doi: 10.5194/cp-10-2007-2014

Wang, P. X., Wang, B., Cheng, H., Fasullo, J., Guo, Z. T., Kiefer, T., \& Liu, Z. Y. (2017). The global monsoon across time scales: Mechanisms and outstanding issues. Earth-Science Reviews, 174, 84-121. doi: 10.1016/ j.earscirev.2017.07.006

Wei, H.-H., \& Bordoni, S. (2016). On the Role of the African Topography in the South Asian Monsoon. Journal of the Atmospheric Sciences, 73(8), 3197-3212. Retrieved from http://journals.ametsoc.org/doi/10.1175/ JAS-D-15-0182. 1 doi: 10.1175/JAS-D-15-0182.1

Wei, H.-H., \& Bordoni, S. (2018). Energetic Constraints on the ITCZ Position in Idealized Simulations With a Seasonal Cycle. Journal of Advances in Modeling Earth Systems, 10(7), 1708-1725. doi: 10.1029/2018MS001313

Wheeler, M., \& Kiladis, G. N. (1999). Convectively coupled equatorial waves: Analysis of clouds and temperature in the wavenumber-frequency domain. Journal of the Atmospheric Sciences, 56(3), 374-399. doi: 10.1175/ 1520-0469(1999)056 〈0374:CCEWAO $\rangle$ 2.0.CO;2

White, R., Battisti, D., \& Skok, G. (2017). Tracking precipitation events in time and space in gridded observational data. Geophysical Research Letters, $44(16)$, 8637-8646.

Wolff, E. W., Chappellaz, J., Blunier, T., Rasmussen, S. O., \& Svensson, A. (2010). Millennial-scale variability during the last glacial: The ice core record. Quaternary Science Reviews, 29, 2828-2838.

Wu, M.-L. C., Reale, O., Schubert, S. D., Suarez, M. J., \& Thorncroft, C. D. (2012). African easterly jet: Barotropic instability, waves, and cyclogenesis. Journal of Climate, 25(5), 1489-1510. 
Wu, R., \& Wang, B. (2001). Multi-stage onset of the summer monsoon over the western North Pacific. Climate Dynamics, 17(4), 277-289. doi: 10.1007/ s003820000118

Xiang, B., Zhao, M., Ming, Y., Yu, W., \& Kang, S. M. (2018). Contrasting impacts of radiative forcing in the Southern Ocean versus southern tropics on ITCZ position and energy transport in one GFDL climate model. Journal of Climate, 31(14), 5609-5628. doi: 10.1175/JCLI-D-17-0566.1

Yang, G.-Y., Methven, J., Woolnough, S., Hodges, K., \& Hoskins, B. (2018). Linking African easterly wave activity with equatorial waves and the influence of Rossby waves from the Southern Hemisphere. Journal of the Atmospheric Sciences, 75 (6), 1783-1809.

Zhai, J., \& Boos, W. R. (2017). The drying tendency of shallow meridional circulations in monsoons. Quarterly Journal of the Royal Meteorological Society, 143(708), 2655-2664. doi: 10.1002/qj.3091

Zhang, C. (2005). Madden-Julian oscillation. Reviews of Geophysics, 43(2).

Zhang, C., Nolan, D. S., Thorncroft, C. D., \& Nguyen, H. (2008). Shallow meridional circulations in the tropical atmosphere. Journal of Climate, 21(14), 3453-3470. doi: 10.1175/2007JCLI1870.1

Zhang, G., \& Wang, Z. (2013). Interannual variability of the Atlantic Hadley circulation in boreal summer and its impacts on tropical cyclone activity. Journal of Climate, 26(21), 8529-8544. doi: 10.1175/JCLI-D-12-00802.1

Zhang, R., \& Delworth, T. L. (2005). Simulated tropical response to a substantial weakening of the Atlantic thermohaline circulation. Journal of Climate, 18(12), 1853-1860. doi: 10.1175/JCLI3460.1

Zhang, S., \& Wang, B. (2008). Global summer monsoon rainy seasons. International Journal of Climatology, 28, 1563-1578. doi: 10.1002/joc.1659

Zhou, W., \& Xie, S.-P. (2018). A Hierarchy of Idealized Monsoons in an Intermediate GCM. Journal of Climate, 31, 9021-9036. Retrieved from http:// journals.ametsoc.org/doi/10.1175/JCLI-D-18-0084.1 doi: 10.1175/JCLI -D-18-0084.1 